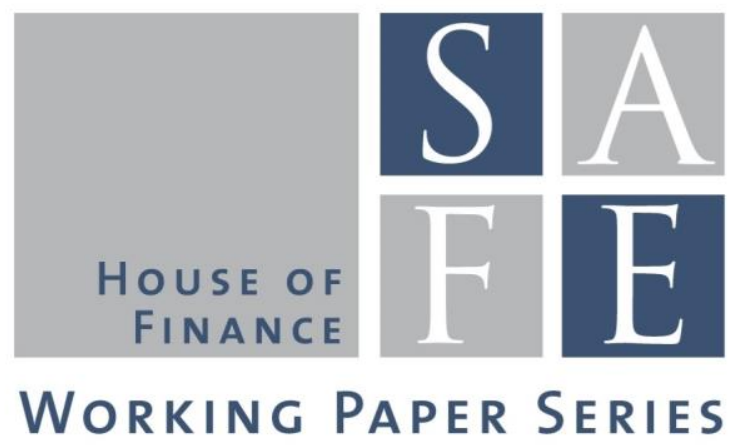

Monica Billio - Michael Donadelli - Antonio Paradiso - Max Riedel

\title{
Which Market Integration Measure?
}

SAFE Working Paper No. 159

\section{SAFE I Sustainable Architecture for Finance in Europe}




\section{Non-Technical Summary}

Changes in the degree of integration among international equity markets affect decisions of policymakers, investors and households alike. Financial integration has, thus, received an enormous amount of attention - much of it devoted to measuring it. A key challenge with this respect consists in finding an integration measure that balances the trade-off between computational complexity and measurement accuracy.

The objective of this study is to compare and rank the financial integration patterns that are generated by applying different empirical methodologies. Our contribution is twofold. First, we examine the degree of heterogeneity in the information captured by different measures over time. Second, we relate the integration patterns produced by the measures with financial integrationdriven phenomena. More precisely, we evaluate the performance of each measure by relying on an established international finance result: "Financial integration leads to declining international portfolio diversification benefits." This approach allows us to quantitatively evaluate the ability of each integration measure in explaining de facto integration.

The measures of integration considered in this work include: (i) the standard unconditional correlation; (ii) the percentage of variance explained by the first principal component; (iii) the multifactor adjusted R-square; (iv) the correlation coefficient adjusted for stochastic interdependence in the sense of Ball and Torous; ( $v$ ) the volatility-adjusted correlation introduced by Forbes and Rigobon; (vi) the correlation coefficient accounted for stochastic volatility using a BEKK-GARCH model specification; (vii) the dynamic conditional correlation in a DCC-GARCH model; (viii) the conditional time-varying beta from a one-factor model.

All measures of integration are applied to monthly equity market data for three different country groups: developed markets (period: 1973-2016), emerging markets (1990-2016), and developed plus emerging markets (1990-2016), totaling to 27 countries.

The results can be summarized as follows. First, all measures give rise to a very similar long-run integration pattern. Overall, we observe that integration has been increasing in the past decades and only in the aftermath of the 2008 Financial crisis markets became less integrated. Second, the standard correlation explains variations in diversification benefits as well or better than more sophisticated measures. This observation suggests that for studying the long-run integration

process, one is well advised to choose the standard correlation over more computationally intensive measures. 


\title{
Which Market Integration Measure?*
}

\author{
M. BILLIO,${ }^{\dagger}$ M. DONADELLI, A. PARADISO and M. RIEDEL ${ }^{\ddagger}$
}

\begin{abstract}
This paper compares the dynamics of the financial integration process as described by different empirical approaches. To this end, a wide range of measures accounting for several dimensions of integration is employed. In addition, we evaluate the performance of each measure by relying on an established international finance result, i.e., increasing financial integration leads to declining international portfolio diversification benefits. Using monthly equity market data for three different country groups (i.e., developed markets, emerging markets, developed plus emerging markets) and a dynamic indicator of international portfolio diversification benefits, we find that $(i)$ all measures give rise to a very similar long-run integration pattern; $(i i)$ the standard correlation explains variations in diversification benefits as well or better than more sophisticated measures. These findings are robust to a battery of robustness checks.
\end{abstract}

Keywords: Equity market integration, dynamic correlation, principal components, international diversification benefits

JEL Codes: F15, F44, G15

*An earlier version of this paper circulated under the title "Measuring Financial Integration: Lessons from the Correlation"

${ }^{\dagger}$ Corresponding author: Ca'Foscari University of Venice, Department of Economics, Cannaregio 873, 30135, Venice, Italy. Tel.: 041234 9152. E-mail: billio@unive.it.

${ }^{\ddagger}$ Monica Billio and Antonio Paradiso are affiliated with Ca’ Foscari University of Venice, Department of Economics. Michael Donadelli and Max Riedel are both at the Research Center SAFE, Goethe University Frankfurt. Authors' phone numbers (e-mails): Tel. +39 0412349152 (billio@unive.it); Tel. +49 6979833882 (michael.donadelli@gmail.com); Tel. +39 0412349161 (antonio.paradiso@unive.it); Tel. +4969798 30046 (riedel@safe.uni-frankfurt.de). We thank for helpful comments on earlier versions Guglielmo Maria Caporale, Roberto Casarin, Alessio Ciarlone, Fulvio Corsi, Giuliano Curatola, Daniele Massacci, Faek Menla Ali, Renatas Kizys, Saten Kumar, Loriana Pelizzon, Christian Schlag, participants of the 11th BMRC-DEMS Conference on Macro and Financial Economics/Econometrics and 39th AMASES Annual Meeting. We also thank two anonymous referees for their comments which substantially improved the paper. We gratefully acknowledge financial support from the project SYRTO, funded by the European Union under the 7th Framework Programme (FP7-SSH/2007-2013 Grant Agreement No. 320270) and the project MISURA, funded by the Italian MIUR. Donadelli and Riedel also gratefully acknowledge financial support from the Research Center SAFE, funded by the State of Hessen initiative for research LOEWE. The authors alone are responsible for the views expressed in the paper and for any errors that may remain. 


\section{Introduction}

International financial markets have become increasingly integrated over the last 30 years. An increasing degree of financial integration across countries and regions provides both advantages and disadvantages. On the one side, a relatively high level of integration (i.e., complete international financial markets) increases risk-sharing opportunities by allowing for larger insurance benefits and more efficient consumption smoothing (see, among others, Jappelli and Pistaferri, 2011; Suzuki, 2014). In this respect, financial integration may generate both short- and long-run welfare benefits (Colacito and Croce, 2010; Yu, 2015). On the other side, the increasing level of global financial integration induces strong positive cross-country equity return correlations. As a result, the benefits from international portfolio diversification decrease (Goetzmann et al., 2005; Christoffersen et al., 2012; Donadelli and Paradiso, 2014). Moreover, increasing financial integration and frictionless international capital markets tend to affect countries' specific policy targets. Blanchard et al. (2010), for instance, argue that the current international financial markets environment may undermine domestic policies' effectiveness.

Financial integration has thus received an enormous amount of attention, much of it devoted to measuring it. Both, policymakers and investors need an instrument that is able to measure integration and its evolution over time. A key challenge consists in finding an integration measure that balances the trade-off between computational complexity and measurement accuracy. As there are many possible measures of financial integration, it is natural to ask whether they all provide similar results in terms of integration levels and patterns, and whether some might be more preferred to others.

The objective of this study is to compare the financial integration patterns that are generated using different empirical methodologies. A large body of literature proposes novel integration measures, while another employs existing measures to capture either regional or global financial integration. To our knowledge, there exists no study that attempts to compare and rank all these measures. Our contribution is therefore twofold. First, we examine the degree of heterogeneity in the information provided by different measures over time. Loosely speaking, we ask whether these measures provide similar equity market integration patterns. Second, we relate the integration patterns reproduced by different measures with financial integrationdriven phenomena. More precisely, we examine the relationship between integration patterns 
and a dynamic international diversification benefits indicator introduced by Christoffersen et al. (2011, 2012). This allows us to quantitatively evaluate the ability of each integration measure in explaining de facto integration.

To account for all possible dimensions of integration, a relatively large number of existing indicators is considered. Table 1 (Panel A) presents a list of main measures proposed by the literature over the last ten years - and employed in this study - along with their properties. Being largely accepted that integration is a dynamic concept, we consider exclusively methodologies that allow us to capture the evolution of the degree of equity market integration over time. Our simplest measure of integration is the standard correlation (henceforth $S C$ ). Since the $S C$ has been largely criticized as measure of integration (see, among others, Bekaert et al., 2009; Pukthuanthong and Roll, 2009; Volosovych, 2011), two recently introduced robust PCA-based measures are used: $(i)$ the percentage of variance explained by the first principal component used by Volosovych (2011), henceforth 1stPC, and (ii) the multi-factor cross-country average adjusted R-square proposed by Pukthuanthong and Roll (2009), henceforth $\bar{R}^{2}$. To account for stochastic interdependence (i.e., the linkage between the correlation and stock return volatilities might be stochastic and varying over time), the methodology of Ball and Torous (2006) is also considered. In addition, we rely on a battery of widely used heteroskedasticity-adjusted measures. Specifically, we employ $(i)$ the volatility-adjusted correlation introduced by Forbes and Rigobon (2002); (ii) the BEKK-GARCH model along the lines of Engle and Kroner (1995); (iii) the dynamic conditional correlation model (DCC-GARCH) proposed by Engle and Sheppard (2001) and Engle (2002); and (iv) a conditional time-varying beta. Improvements with respect to existing studies are also carried out (see Table 1, Panel B). The volatility-adjustment in the $S C$ is introduced by relying on the key events embedded in the US and EU economic policy uncertainty indexes proposed by Baker et al. (2015). This allows us to account for multiple changes in volatility, which correspond to major political and financial market events. ${ }^{1}$ For robustness, the $\bar{R}^{2}$ and 1 stPC are re-computed by accounting for stochastic interdependence. In other words, in both PCA-based measures the sample correlation is substituted with the correlation obtained via Ball and Torous (2006)'s procedure. This helps capturing integration during non-tranquil and tranquil times (Ball and Torous, 2006). Based on the ongoing debate on whether or not the $S C$ represents a robust measure of integration (Carrieri et al., 2007;

\footnotetext{
${ }^{1}$ This differs from Forbes and Rigobon (2002) who focus on a single shift in the variance level.
} 
Pukthuanthong and Roll, 2009; Volosovych, 2011), this study uses the latter as a benchmark indicator of financial integration.

To ensure that our analysis is general and does not strictly depend on the chosen sample, we implement all the measures listed in Table 1 by using data for three groups of countries: (i) developed markets (DMs); (ii) emerging markets (EMs) and (iii) developed plus emerging markets (ALL). While the first two groups consist of countries displaying similar characteristics in terms of volatility patterns and average returns, the third group includes economies with a large variety of sizes, degrees of openness, and financial market characteristics. We stress that this classification allows us to examine the evolution of equity market integration in DMs and EMs as well as global equity market integration. Therefore, we bridge the literature focusing exclusively on regional integration (Yu et al., 2010; Bekaert et al., 2011; Volosovych, 2011; Donadelli and Paradiso, 2014) and those studies examining global equity market integration dynamics (Carrieri et al., 2007; Pukthuanthong and Roll, 2009).

Table 1: Financial integration measures: EXisting Studies AND MEASURES' Characteristics

\begin{tabular}{|c|c|c|c|c|c|}
\hline $\begin{array}{l}\text { PANEL A: } \\
\text { Measure }\end{array}$ & Studies on Financial Integration & Dynamic & $\begin{array}{c}\text { Comov. } \\
\text { Bias }\end{array}$ & Heterosk. & $\begin{array}{c}\text { Stochastic } \\
\text { Interdep. }\end{array}$ \\
\hline$S C$ & Goetzmann et al. (2005); Quinn and Voth (2008) & $\mathrm{X}$ & & & \\
\hline $\bar{R}^{2}$ & Pukthuanthong and Roll (2009); Yu et al. (2010) & $\mathrm{x}$ & $\mathrm{X}$ & & \\
\hline $1 s t P C$ & Volosovych (2011); Volosovych (2013) & $\mathrm{X}$ & $\mathrm{X}$ & & \\
\hline Corr. (ASI) & Ball and Torous (2006) & $\mathrm{X}$ & & & $\mathrm{X}$ \\
\hline Forbes-Rigobon Corr. & Connolly et al. (2007) & $\mathrm{X}$ & & $\mathrm{X}$ & \\
\hline DCC-GARCH & Chiang et al. (2007); Wang and Moore (2008); Egert and Kocenda (2011) & $\mathrm{X}$ & & $\mathrm{X}$ & \\
\hline BEKK-GARCH & Caporale and Spagnolo (2011); Bekiros (2013) & $\mathrm{X}$ & & $\mathrm{X}$ & \\
\hline Cond. Beta & Choudhry and Jayasekera (2013); Jayasinghe et al. (2014) & $\mathrm{X}$ & & $\mathrm{X}$ & \\
\hline \multicolumn{6}{|l|}{ PANEL B: } \\
\hline$R^{2}(\mathrm{ASI})$ & This paper & $\mathrm{X}$ & $\mathrm{X}$ & & $\mathrm{X}$ \\
\hline $1 s t P C(\mathrm{ASI})$ & This paper & $\mathrm{X}$ & $\mathrm{X}$ & & $\mathrm{X}$ \\
\hline Forbes-Rigobon Corr. & This paper & $\mathrm{X}$ & & $\mathrm{X}^{*}$ & \\
\hline
\end{tabular}

Notes: Panel A lists the methodologies (and their respective technical features) employed by the international finance literature to measure equity market integration over time. Panel B reports newly introduced measures. *The volatility-adjustment is introduced by relying on the set of relevant political and financial events indicated in the US and EU economic policy uncertainty indexes (see Baker et al., 2015).

A natural question one might ask is then the following: how can we evaluate the effectiveness of these measures in capturing de facto financial integration? To some extent financial integration is an abstract concept and measuring it realistically is challenging. From a quantitative point of view, it is therefore difficult to state that one measure is better than another. At present, the international finance literature does not provide any quantitative assessments on existing measures' ability in capturing real financial integration dynamics. With this study, 
we also aim to fill this gap.

A suggestion on how to build a ranking scheme allowing us to quantitatively compare integration indicators' performances comes from an established international finance literature result: to a rise in global market integration corresponds a drop in international portfolio diversification benefits (see, among many others, Longin and Solnik, 1995; Errunza et al., 1999; Driessen and Laeven, 2007; Bekaert et al., 2009; Christoffersen et al., 2012). While many studies simply argue that the increasing comovement between international equity market returns may lead to decreasing diversification benefits, only one study proposes a dynamic international diversification benefits metric. Christoffersen et al. (2011, 2012) build a dynamic volatility-based conditional diversification benefits measure (henceforth $V-C D B$ ) for three country groups. We base our ranking procedure on their measure as follows. First, following Christoffersen et al. (2011, 2012), we compute an indicator of dynamic diversification benefits for each country group. Second, via standard empirical analyses, we examine whether there is a link between the integration pattern generated by the proposed measures and diversification benefits. Specifically, we ask whether one measure explains better than another variations in international portfolio diversification benefits (i.e., de facto integration).

Our main results are as follows. First, we observe that the $S C, 1 s t P C$ and $\bar{R}^{2}$ give rise to almost identical equity market integration patterns. Second, heteroskedasticity-adjusted measures tend to produce more volatile integration patterns. Still, over the long-run they give rise to very similar financial integration trends. It turns out that the long-run equity market integration patterns extracted using different statistical methods do not show qualitatively relevant differences. Third, the $S C$, on average, explains movements in international diversification benefits as well as, if not better than, more sophisticated measures (i.e., PCA-based and heteroskedasticity-adjusted measures). We stress that our main findings survive a battery of robustness checks.

The remainder of this paper is organized as follows. Section 2 reviews the literature on financial integration measures. Sections 3 and 4 describe the methodologies and data, respectively. Section 5 compares the financial integration patterns that are generated using different methodologies. Section 6 employs a novel and simple approach to evaluate the ability of the proposed measures in explaining movements in de facto integration. Section 7 provides additional discussions on the advantages and disadvantages of the employed integration measures. 
Section 8 concludes.

\section{Related Literature: A Focus on Financial Integration Measures}

Broadly speaking, the existing financial integration indicators can be classified in three categories: $(i)$ price-based indicators; $(i i)$ quantity-based indicators; and (iii) regulatory (or institutional) measures. Generally, four criteria are used to evaluate the usefulness of the above indicators (Adam et al., 2002): (i) data availability; (ii) reliability of the data on which the indicators are based; (iii) economic meaning of the indicators and $(i v)$ the ease of building and updating the indicators. Based on these criteria, price-based indicators - classified also as direct measures of integration - have attracted more attention than quantity-based indicators (i.e., stock or flow data-based measures), as they satisfy the above conditions. Since price-based indicators invoke the law of one price, they also have a clear-cut interpretation, which is often lacking for those quantity-based indicators relying on flow data (Volosovych, 2011). For these reasons, several studies have focused on the comovement between asset prices (see, among many others, Kim et al., 2006; Carrieri et al., 2007; Bekaert et al., 2009). Hence, although financial integration encompasses many different aspects of complex linkages across various financial markets, our study follows this strand of the international finance literature and relies on international equity prices convergence.

From a methodological point of view, the empirical literature has proposed different measurement frameworks relying on price-based indicators: Vector Auto-Regression (VAR) models (Khalid and Kawai, 2003; Elyasiani and Wanli, 2008; Jayasuriya, 2011), standard cross-country correlation (Watson, 1980; Meric and Meric, 1989; Goetzmann et al., 2005), cointegration and error-correction models (Laopodis, 2011; Gupta and Guidi, 2012), GARCH models (Kim et al., 2006; Carrieri et al., 2007; Wang and Moore, 2008; Egert and Kocenda, 2011), asset pricing models (Nellis, 1982; Mauro et al., 2002; de Jong and de Roon, 2005; Barr and Priestley, 2004; Abad et al., 2010; Volosovych, 2011; Donadelli and Paradiso, 2014), and common component approach (Carrieri et al., 2007; Pukthuanthong and Roll, 2009; Yu et al., 2010). VAR-based studies make use of impulse response analysis to investigate the effects of contagion and the 
degree of interdependence, whereas cointegration-based studies aim to assess the presence of a long-run equilibrium among cross-country financial variables, such as stock or bond prices. Asset pricing models usually rely on a standard CAPM framework and assume that the excess return of a country is generated by global factors (with a coefficient $\xi$ ) and idiosyncratic factors (with a coefficient $1-\xi$ ). In this setting, the parameter $\xi$ is meant to capture equity market segmentation (see, among others, Barr and Priestley, 2004). Cointegration methods, VAR and asset pricing models tend to have major drawbacks. For instance, cointegration and VAR models are not able to produce a numerical measure of financial integration. ${ }^{2}$ Moreover, cointegration methods have been criticized for being static approaches and unable to capture the dynamic evolution of a process (Kearney and Lucey, 2004; Kim et al., 2006; Wang and Moore, 2008). For these reasons, cointegration- and VAR-based metrics do not fit the agenda of this paper.

The $S C$, a conventional measure of comovement, can be easily implemented and has a straightforward interpretation. To summarize comovement in a group of markets, the usual practice is to compute the average of the correlation coefficients estimated for each country-pair (Mauro et al., 2002; Quinn and Voth, 2008). Some studies employ SC over different sub-periods (Goetzmann et al., 2005; Quinn and Voth, 2008). Traditionally, however, the SC implicitly assumes that the relationship between assets does not change over time. Hence, it does not track down the dynamics of the relationship between volatilities. To monitor movements in the volatility across equity markets, dynamic conditional correlation models are generally used (Wang and Moore, 2008; Egert and Kocenda, 2011). However, two issues arise from the use of these models: $(i)$ Longin and Solnik (2001) show that correlation is not related to market volatility per sé but it is mainly affected by the market trend; correlation seems to rise only when asset prices fall (bear markets) and not when they are expected to rise (bull markets); (ii) Forbes and Rigobon (2002) argue that conditional correlation is subject to a volatility bias; the coefficient would increase in periods of high volatility (during crises or shocks) and, as a consequence, may lead to a wrong conclusion that there is a contagion effect during a crisis. Therefore, there is no general consensus on how one should account for conditional heteroskedasticity (Volosovych, 2013).

\footnotetext{
${ }^{2}$ In a cointegrating framework, an error correction representation contains only information on the speed of adjustment to long-run equilibrium but not on the level of integration.
} 
Even if the $S C$ and other correlation-based metrics are still widely used as integration measures, they have been subject to severe criticism. For instance, Bekaert et al. (2009) conclude that "Correlations are an important ingredient in the analysis of international diversification benefits and international financial market integration. Of course, correlations are not a perfect measure of either concept" (p. 2612). In line with Carrieri et al. (2007), Pukthuanthong and Roll (2009) write: "The simple correlation between broad financial market index returns from two countries can be a poor measure of their economic integration" (p. 231). Similarly, Volosovych (2011): “... a conventional measure of comovement, the coefficient of correlation, has limited applicability as a measure of economic integration" (p. 1560). Based on these arguments, Pukthuanthong and Roll (2009) and Volosovych (2011) propose two PCA-based integration measures, which, as they argue, are more robust than the $S C$. Pukthuanthong and Roll (2009) introduce a novel measure based on the explanatory power of a multi-factor model. In their setting, the first ten principal components, which explain close to $90 \%$ of the cross-sectional variation in country returns, are employed as global factors. The $\bar{R}^{2}$ is then computed in each calendar year for each country. The cross-country average $\bar{R}^{2}$ represents then their alternative integration measure. In the spirit of Nellis (1982) and Mauro et al. (2002), Volosovych (2011), instead, uses the proportion of total variation in individual returns explained by the first principal component to measure the degree of financial integration. ${ }^{3} \mathrm{He}$ focuses on the bond market of 15 industrialized economies from 1875 to 2009 and computes the integration dynamics using a rolling window of 156 months. Of course, PCA-based measures may also raise some concerns. For example, among others, the PCA is usually subject to a trade-off between the covariance and the correlation matrix used to derive the components. In the correlation matrix, the variables are standardized. The goal of this simple transformation is to give to all variables an equal weight, even if they exhibit huge variance differences. In general, such transformation is not required when variables have the same unit. To be sure that high changes in the variance will not dominate the principal components, this transformation is often accounted for. Of course, this may represent a non-negligible drawback. Therefore, by using the covariance matrix there can be the risk that variables with high variance will influence

\footnotetext{
${ }^{3}$ Mauro et al. (2002) find that the first principal component explains a large proportion of variation of sovereign bond spreads for a group of emerging market countries from 1877 to 1913 and an even larger proportion in the 1990s. Earlier, Nellis (1982) used PCA to compare interest rate comovement among industrialized countries before and after the move to a floating exchange rate regime in the early 1970s.
} 
the overall analysis.

Apparently, there is no general consensus on how to properly measure financial integration. From this literature review, two main issues remain open: $(i)$ Is there heterogeneity in the set of information provided by all these measures over the long-run? (ii) Do all these measures really capture movements in integration-driven phenomena (e.g., international diversification benefits)? We attempt to address these issues in Sections 5 and 6 .

\section{Measuring Financial Integration}

This section describes the methodologies employed to build the integration measures aimed at capturing regional and global equity market integration dynamics. Specifically, we present in detail all the measures listed in Table 1. Section 3.1 introduces the $S C$. In Section 3.2, we present the two recently developed PCA-based measures (i.e., $\bar{R}^{2}$ and $1 s t P C$ ). In the spirit of Ball and Torous (2006), Section 3.3 introduces the concept of stochastic interdependence and applies it to the $S C, \bar{R}^{2}$ and $1 s t P C$. Finally, Section 3.4 focuses on well-known and widely used heteroskedasticity-adjusted measures (i.e., Forbes-Rigobon, DCC-GARCH, BEKK-GARCH, Conditional Beta).

\subsection{The dynamic $S C$}

The $S C$ is one of the most widespread proxies for measuring international markets comovement and thus financial integration (Kearney and Lucey, 2004). ${ }^{4}$ Additionally, it is very easy to compute and has a straightforward interpretation. Following standard practices, we focus on bilateral correlations. This avoids the choice of a benchmark market. Bilateral correlations are estimated using a rolling window of 60 months. ${ }^{5}$ Our dynamic $S C$ is then defined as the cross-country average correlation, i.e., the average of upper or lower triangular elements in the correlation matrix estimated in each window.

\footnotetext{
${ }^{4}$ Examples of studies using simple correlation include Panton et al. (1976) and Hilliard (1979).

${ }^{5}$ The rolling window length over which correlations are computed can affect the outcome. The window should be wide enough to leave sufficient observations to compute precise correlation coefficients but short enough in order to avoid smoothing out important medium-term changes in integration. In general, the optimal window size cannot be determined analytically but has to be determined from the outset. We fix the rolling window size at 60 months such that it approximates the length of a full business cycle. In any case, our results are robust to varying window lengths (see Appendix A, Figure A.1).
} 


\subsection{Adding robustness}

I. The $\bar{R}^{2}$

Pukthuanthong and Roll (2009) argue that the correlation coefficient may represent an unsuitable measure of integration and show that two countries being perfectly integrated might not display perfect correlation between their returns. As an alternative, they propose a measure based on the explanatory power of a multi-factor linear model. This approach does not rely on any particular asset pricing model but merely requires globally common factors that can be interpreted as non-traded risk factors driving global financial markets. The global factors $f$ are obtained from applying the PCA to international equity returns:

$$
f_{i, t}=v_{i, 1} r_{1, t}+v_{i, 2} r_{2, t}+\ldots v_{i, C} r_{C, t}
$$

where $r_{c, t}$ is the country $c$ 's market return at time $t$ and $v_{i j}$ is the $j$ th element of $i$ th PC, also called scoring coefficient or loading. The first $K<C$ global factors serve then as explanatory variables in a multi-factor regression for all $C$ country index returns. Formally,

$$
r_{c, t}=\beta_{c, 0}+\beta_{c, 1} f_{1, t}+\cdots+\beta_{c, K} f_{K, t}+\epsilon_{n, t}, \quad c \in\{1, \ldots, C\}
$$

where $\beta_{c, k}$ measures country c's exposure to $k$ th global factor. The cross-country average of the $\bar{R}^{2}$ s obtained from the above regressions serves as a robust measure of financial integration. ${ }^{6}$

We acknowledge that our estimation procedure slightly deviates from the original approach. Pukthuanthong and Roll (2009) use daily returns and estimate the eigenvectors for each calendar year separately and apply them to returns in the following calendar year. In doing so, they produce out-of-sample global factors that are then used as explanatory variables in the regressions. The number of global factors is chosen such that they explain close to $90 \%$ of the total volatility in the covariance matrix. Differently, we estimate the cross-country average $\bar{R}^{2}$ using a rolling window of 60 months. Additionally, the correlation matrix instead of the

\footnotetext{
${ }^{6}$ The $\bar{R}^{2}$ as a potential measure of integration has been used also by Yu et al. (2010). However, their common component approach differs from the one developed by Pukthuanthong and Roll (2009) in several dimensions. First, the $\bar{R}^{2}$ is obtained using a 3-year rolling OLS estimation. Second, the employed factors are not represented by principal components (i.e., artificial risk factors) but by four traded factors (i.e., currency returns, excess equity returns, dividend yields and forward premia).
} 
covariance matrix of country returns is used. ${ }^{7}$ To be homogeneous, we decide to employ $K=3$ in-sample global factors in each window and for each country group. On average, the first 3 PCs explain around $70 \%$ of total returns variation. ${ }^{8}$

\section{The $1 s t P C$}

Volosovych (2011) proposes an alternative PCA-based measure. He argues that the proportion of total variation in individual equity returns explained by the 1 stPC - dynamically extracted using a rolling window approach - can be employed to capture de facto integration (see also Nellis, 1982; Mauro et al., 2002). This approach has several advantages: $(i)$ it accounts for several dimensions of integration including comovement and segmentation; $(i i)$ it is robust to the presence of outliers or heavy-tailed distributions and the choice of a reference country; and (iii) it has a clear theory-based interpretation.

The estimation procedure is straightforward. The initial steps correspond to the ones needed for computing the $\bar{R}^{2}$. What is different here is that instead of performing a PCA-based regression, Volosovych (2011) assumes that the variation explained by the 1 stPC can serve as a measure of financial integration. Formally,

$$
\text { Variation explained by } 1 \text { st } P C=\frac{\lambda_{1}}{\sum_{i=1}^{C} \lambda_{i}},
$$

where $\lambda_{i}$ is the eigenvalue of $i$ th $\mathrm{PC}$. The intuition behind this approach is that financial market integration can be captured by the proportion of countries' returns explained by an unobserved factor. We stress that the measures proposed by Pukthuanthong and Roll (2009) and Volosovych (2011) are very similar. In particular, under certain assumptions, these two approaches yield identical results (see, Jong and Kotz, 1999). In Appendix B, we illustrate this by using a "two country-one PC example".

\footnotetext{
${ }^{7}$ The correlation matrix is used to account for large variations across country returns' variances. In doing this, we avoid the dominance of a single PC. Note that the use of the covariance matrix gives rise to similar cross-country average $\bar{R}^{2}$ dynamics (see Appendix A, Figure A.2).

${ }^{8}$ In particular, the first 3 PCs capture up to $80 \%$ of returns variation among DMs over the period $2005-2015$ and around $70 \%$ of return variation among EMs and ALL during the mid-90's. Of course, the percentage of volatility in the correlation matrix explained by the 3 PCs is increasing over time for each country group. Note that using more or less factors still provides a similar pattern of growing integration (see also Pukthuanthong and Roll, 2009). In particular, with more (less) factors the $\bar{R}^{2}$ s are slightly higher (lower).
} 


\subsection{Accounting for Stochastic Interdependence}

I. The $S C$ (ASI)

Existing empirical studies document a positive linkage between correlation and volatility (King et al., 1994; Ramchand and Susmel, 1998; Morana and Beltratti, 2008). Longin and Solnik (1995), for instance, provide evidence of instability in the correlation patterns characterizing international stock markets. They observe that the volatility and correlation increased in correspondence of the October 1987 stock market crash. Particularly, the correlation remained on a relatively high level afterwards, while volatility reverted to pre-crash levels. Forbes and Rigobon (2002) argue that changes in market volatility can bias the correlation coefficient and introduce a correction term in order to obtain its unconditional counterpart. They employ the newly obtained cross-market correlations to test for contagion effects during stock market crises. Contagion is assumed to take place only if market interdependence (i.e., strong linkages that exist in all states of the world) exhibits a significant change during a crisis. While the authors' analysis is characterized by a constant covariance structure in returns, Ball and Torous (2006) take into account the time-varying and stochastic nature of covariances. In the following, we present the latter approach while the former is employed further below.

Similarly to Forbes and Rigobon (2002), Ball and Torous (2006) argue that using the correlation coefficient for measuring the comovement of stock markets might yield potentially biased results. In order to account for this problem, the authors introduce a linear state-space model in which they explicitly differentiate between measured variables and their population counterparts. We follow this approach and use this model:

$$
\begin{array}{cc}
y_{t}=\quad \alpha_{t}+\epsilon_{t}, & \operatorname{var}\left(\epsilon_{t}\right)=H, \\
\alpha_{t}=T \alpha_{t-1}+\eta_{t}, & \operatorname{var}\left(\eta_{t}\right)=Q,
\end{array}
$$

where $y_{t}=\left\{\log \sigma_{i, t}^{2}, \log \sigma_{j, t}^{2}, z_{i, j, t}\right\}$ is the observation vector of $\log$ variances and Fisher trans-

form $z_{i, j}=\frac{1}{2} \log \frac{1+\rho_{i j}}{1-\rho_{i j}}$ of the sample correlation $\rho_{i j}$, for countries $i$ and $j$. The measurement Eq. (4) links $y_{t}$ with its population counterpart $\alpha_{t}$. The measurement errors $\epsilon_{t}$ are assumed to be identically and independently distributed with non-diagonal covariance matrix $H$. The 
transition Eq. (5) models the stochastic evolution of $\alpha_{t}$ with transition matrix $T$ and residual error terms $\eta_{t}$ with covariance matrix $Q$. We assume non-diagonality in $H$ and $Q$. The former specification allows measurement errors to be correlated. The latter takes into account the stochastic interdependence between markets.

Following Ball and Torous (2006), the covariance matrices $H$ and $Q$ as well as the transition matrix $T$ are estimated by applying the Kalman filter in combination with the EM Algorithm. ${ }^{9}$ The population correlation is then obtained by computing the inverse of the Fisher transform using Broyden's Method. Our estimation procedure differs from the one originally proposed by Ball and Torous (2006) in several aspects. The authors measure volatilities and correlations by dividing the whole time series sample of daily returns into sequential non-overlapping intervals. The countries' return volatilities and the respective bilateral return correlations are assumed to be constant within each interval but are allowed to vary across the resultant intervals. Differently, we estimate volatilities and correlations using monthly returns with overlapping intervals of length 60 months (i.e., rolling windows). Within each window, the moments are assumed to be constant but allowed to vary across the rolling windows. ${ }^{10}$ The cross-country average of the rolling population correlation serves us as a new measure of financial market integration that accounts for cross-market stochastic interdependence (ASI).

\section{The $\bar{R}^{2}(\mathrm{ASI})$ AND $1 s t P C(\mathrm{ASI})$}

The estimation of $\bar{R}^{2}$ and 1 stPC relies on the PCA which, in turn, uses the return correlation matrix as input. Using the above estimation results, we are able re-calculate the two measures in order to accommodate stochastic interdependence between markets. In practice, we substitute the sample correlations (i.e., measured correlations) by their population counterparts. This is repeated for each rolling window while all other calculation steps remain unaffected. We refer to these adjusted measures as: the $\bar{R}^{2}(\mathrm{ASI})$ and the 1 stPC (ASI).

\footnotetext{
${ }^{9}$ The estimation methodology goes along the lines described in the Appendix of Ball and Torous (2006). First, we fit univariate linear state space models for each of the three series. Using the estimated coefficients, we run the EM algorithm with 150 iterations in the multivariate case. Then, the EM estimates are used as starting values in the Broyden-Fletcher-Goldfarb-Shanno (BFGS) algorithm. We also employ the Choleski factorization of $H$ and $Q$ to ensure positive definiteness.

${ }^{10} \mathrm{In}$ our view, this can be interpreted as a low-frequency long-run mean estimation of volatilities and correlations across a cycle. For robustness, we also apply the original approach using five month non-overlapping intervals. The resulting equity market integration dynamics are very similar and are available upon request.
} 


\subsection{Accounting for Heteroskedasticity}

\section{Forbes-RIgobon}

When studying contagion in financial markets, Forbes and Rigobon (2002) find larger crosscountry correlation when common volatility is high. They argue that correlations are biased by heteroskedasticity. In particular, volatilities rise during crises leading to an artificial upwardbias in correlations. In order to correct for the bias, the authors propose a volatility-adjusted correlation coefficient which takes the following form:

$$
\rho_{t}^{F R}=\frac{\rho_{t}}{\sqrt{1+\delta_{t}\left[1-\left(\rho_{t}\right)^{2}\right]}},
$$

where $\rho_{t}$ is the Pearson correlation, and $\delta_{t}$ is the increase in the variance of the returns in a pre-specified time-interval relative to the period with the minimum variance.

Our estimation procedure goes as follows. As for the $S C$, we fix the rolling window at 60 months and compute the average volatility across all countries. Within each rolling window, we obtain the variance correction $\delta$ using 24 month intervals. Finally, we correct the cross-country average correlation using $\delta$ and plot the resulting volatility-corrected correlation $\rho^{F R}$.

In line with the original argument of Forbes and Rigobon (2002), we account for this volatility adjustment only in the presence of major international financial and political events. To this end, we rely on the US and EU economic policy uncertainty indices developed by Baker et al. (2015) and consider the following events: Second Oil Price Shock (July 1979-April 1980); 1980s US Recession (July 1981-November 1982); Black Monday (October 1987-November 1987); 1st Gulf War (August 1990-February 1991); Japan Stock Price Crisis (January 1992-January 1993); Asian and Russian Crises (July 1997-March 1999); 9/11 (August 2001-November 2001);

Invasion of Iraq (March 2003-May 2003); Great Recession (December 2007-June 2009); EU Sovereign Debt Crisis (July 2011-December 2011); Greek Default Risk (January 2015-August 2015); Stock Market Crash in China (July 2015-September 2015).

\section{BEKK}

An alternative approach to measuring the extent of market integration in terms of volatility is the application of the multivariate Baba-Engle-Kraft-Kroner (BEKK) model proposed by 
Engle and Kroner (1995). For stationary return series, ARMA models can be employed to model the mean while GARCH models can be used to capture the time-varying volatilities of each return series. In the following, we assume that the conditional mean of country $i$ 's return $r_{i, t}$ follows an $\operatorname{ARMA}(1,1)$ process, ${ }^{11}$ (i.e., $\left.r_{i, t}=\mu_{i}+\phi_{i} r_{i, t-1}+\theta_{i} e_{i, t-1}+e_{i, t}\right)$. The error vector $e_{t}$ is conditionally normal with mean zero and time-varying variance-covariance matrix $H_{t}=\left[h_{i j, t}\right]$. The BEKK-GARCH $(1,1)$ model assumes that the covariance matrix can be decomposed as

$$
H_{t}=C C^{\prime}+A^{\prime} e_{t-1} e_{t-1}^{\prime} A+G^{\prime} H_{t-1} G,
$$

where $C, A$ and $G$ are $N \times N$ parameter matrices and $C$ is upper triangular. Note that the conditional variances $\left(h_{i i, t}\right)$ and the conditional covariances $\left(h_{i j, t}\right)$ depend on lagged values of conditional variances $\left(h_{i i, t-1}\right)$ and the conditional covariances $\left(h_{i j, t-1}\right)$, as well as on lagged values of squared errors of both series and the cross-products of the errors. This feature distinguishes the BEKK-GARCH model from the univariate GARCH model (Horvath and Petrovski, 2013). By employing a bivariate BEKK-GARCH$(1,1)$ model specification, we estimate timevarying variances and covariances pairwise between local market returns and then compute the conditional correlations.

\section{DCC-GARCH}

The DCC-GARCH proposed by Engle and Sheppard (2001) and Engle (2002), is another model for examining correlation dynamics among assets. It belongs to the family of multivariate GARCH models and represents an extension of the Constant Conditional Correlations model (CCC) proposed by Bollerslev (1990). The DCC approach calculates the current correlation between variables as a function of past realizations of volatility within the variables as well as the correlations between the variables. The model is designed to allow for two stage estimation, where in the first stage univariate GARCH models are estimated for each residual series. In the second stage, residuals, transformed by their standard deviation estimated during the first stage, are used to estimate the parameters of the dynamic correlation. Analogous to the BEKK model, DCC requires standardized residuals from the mean-variance specification of each return

\footnotetext{
${ }^{11}$ The estimation was also conducted using the BIC criterion to determine optimal $p$ and $q$ for an ARMA(p,q) process. The results do not yield any qualitative improvement and are included in the robustness section (see Appendix A, Figure A.3)
} 
series. Again, we employ an $\operatorname{ARMA}(1,1)$ specification with a conditionally normal error $e_{t}$ with mean zero and a variance-covariance matrix that is decomposable into time-varying correlations and standard deviations. Further, we assume that the variances follow a $\operatorname{GARCH}(1,1)$. Then, the DCC correlation specification is given as

$$
R_{t}=\operatorname{diag}\left\{Q_{t}\right\}^{-1 / 2} Q_{t} \operatorname{diag}\left\{Q_{t}\right\}^{-1 / 2}
$$

where $Q_{t}=\left[q_{i j, t}\right]$ is a symmetric positive definite variance-covariance matrix of the GARCH residuals. As for the standard correlation, this GARCH-based indicator of financial integration is computed by averaging all the dynamic conditional country-pair correlations.

\section{Conditional Time-Varying Beta}

Previous literature suggests to employ the beta, as measured in the CAPM, in order to gauge the extent of market integration (see, among others, Koedijk et al., 2002; De Santis and Gérard, 1998). In the following, we model the expected returns on each local equity market as a function of its conditional covariance with the returns on the global market portfolio. We decide to apply the following conditional one-factor model

$$
E_{t-1}\left[r_{i, t}\right]=\frac{\operatorname{Cov}_{t-1}\left(r_{i, t}, r_{m, t}\right)}{\operatorname{Var}_{t-1}\left(r_{m, t}\right)} E_{t-1}\left[r_{m, t}\right]
$$

where $r_{i}$ and $r_{m}$ represent the local equity and the global market, respectively. Application of this model requires the specification and estimation of the conditional variances. However, assetpricing theories do not specify how the conditional second moments should be modeled. Given the vast literature documenting that equities exhibit volatility clustering and leptokurtosis, and due to the estimation advantages of a simple GARCH framework, as pointed out by De Santis and Gérard (1998), we decide to employ a bivariate version of BEKK-GARCH(1,1) model. We estimate the conditional sensitivities of local equity market index returns to changes in the global portfolio for each country separately. The MSCI World Index is used as a proxy for the global market portfolio. The cross-country averaged Conditional Beta serves then as proxy for equity market integration. 


\section{Data}

Our sample consists of data representing three groups of countries: (i) DMs; (ii) EMs and (iii) ALL. Specifically, we use monthly Total Return Indices (i.e., reinvested dividends are included) from Level 1 (i.e., Market) of Datastream Global Equity Indices (DGEI) for the following countries $^{12}$

- DMs: Australia, Austria, Belgium, Canada, Denmark, France, Germany, Hong Kong, Ireland, Italy, Japan, Netherlands, Singapore, Switzerland, United Kingdom and United States (16 countries);

- EMs: Chile, India, Indonesia, Korea, Malaysia, Mexico, Philippines, South Africa, Taiwan, Thailand and Turkey (11 countries);

- ALL: 16 DMs + 11 EMs (27 countries).

DMs and EMs data run from January 1973 to January 2016 and from May 1990 to January 2016, respectively. We use monthly data in line with existing studies focusing on time-varying market integration (see, among others, Barr and Priestley, 2004; de Jong and de Roon, 2005; Carrieri et al., 2007; Yu et al., 2010; Volosovych, 2011). Note also that monthly data, instead of daily data, are employed to avoid a set of common high-frequency data issues: $(i)$ presence of zero returns; (iii) non-synchronicity and (ii) excess noise (in particular, in the case of the EMs data). ${ }^{13}$ Country equity market returns are computed from TRI as follows, $r_{c, t}=\left[\left(T R I_{c, t} / T R I_{c, t-1}\right)-1\right]$, where $T R I_{c, t}$ is the return index of country $c$ at time $t .^{14}$

We stress that our sample is homogeneous. First, the set of countries belonging to each group does not change over time. Second, differently from other studies, we use exclusively TRIs that are, of course, preferable. Let us remark that our country classification allows to examine integration dynamics in both developed and emerging markets as well as global market integration. ${ }^{15}$ To account for all possible sources of comovement between international equity

\footnotetext{
${ }^{12}$ Note that DGEI have been widely used by the international finance literature (see, for instance, Baca et al., 2000; Brooks and Negro, 2004; Donadelli and Paradiso, 2014).

${ }^{13}$ In this respect, Pukthuanthong and Roll (2009) write: "There are reasons (thin trading and other microstructure effects) to think that longer return intervals might be better even though the number of observations would be reduced" (p. 230). See also Bekaert et al. (2009) on this issue.

${ }^{14}$ Note that the use of different stock market indexes (i.e., OECD Share Price Indexes, Morgan Stanley Capital International (MSCI) Total Return Indices) does not alter the paper's main results.

${ }^{15}$ A similar classification can be found in Christoffersen et al. (2012).
} 
Developed Markets

FDI

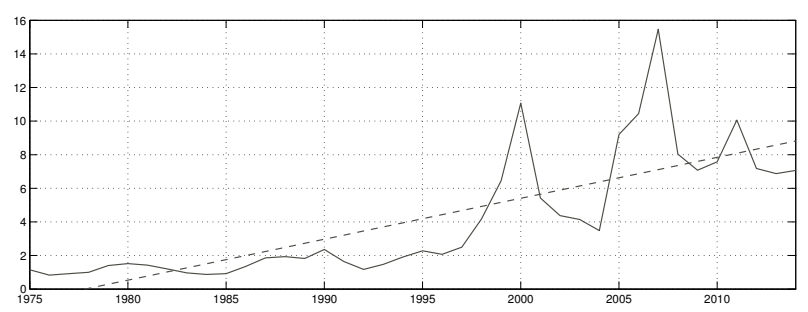

TRADE

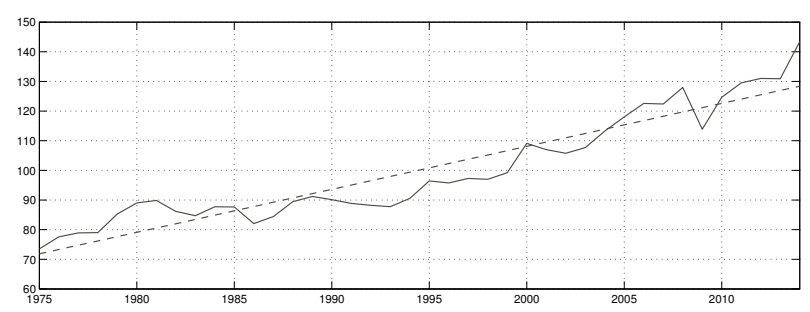

StOCKS TRADED

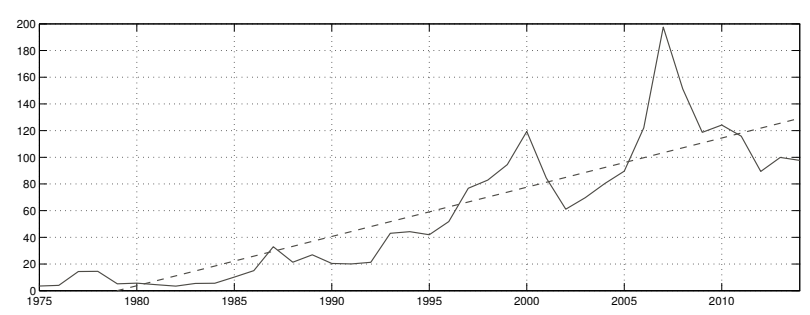

EMERGING MARKETS

FDI

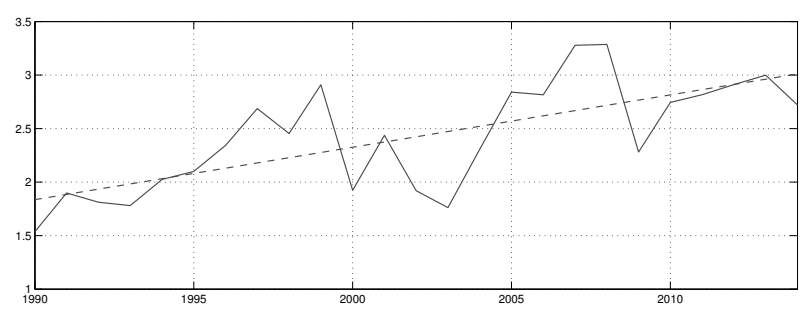

TRADE

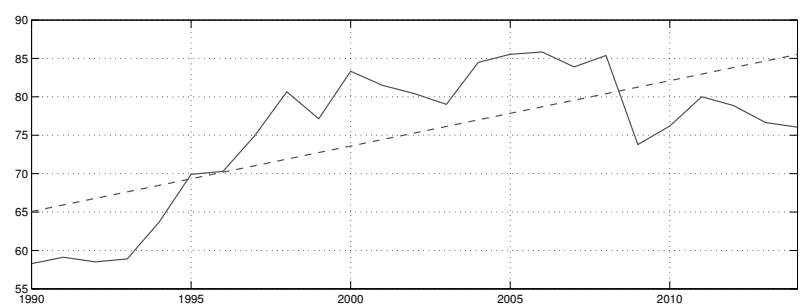

STOCKS TRADED

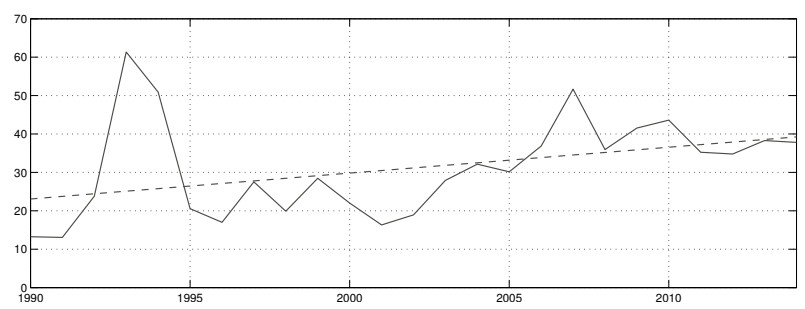

Notes: This figure reports the evolution of the total trade (sum of import and exports as a \% of GDP), foreign direct investment (FDI, net inflows, as \% of GDP) and stocks traded (market value, as \% of GDP) in DMs and EMs (excluding Taiwan). The dashed lines represent linear trends. Data are annual and run from 1974 (or later) to 2012. Source: World Development Indicators (World Bank).

returns - including changes in cross-country currency variations - our TRIs are denominated in local currency (see Volosovych, 2011). Finally, note that the period covered in this study $(i)$ is characterized by an increasing degree of financial and trade market openness (see Figure 1) and $(i i)$ includes relevant international economic and political events (e.g., II Oil Price Shock in July 1979; Black Monday in October 1987; 1st Gulf War in December 1990; Russian financial crisis in August 1998; China WTO entry in October 2000; 9/11 terrorist attacks in September 2001; Lehman Chapter 11 in September 2008; EU sovereign debt crisis, among others). 


\section{Comparing Financial Integration Measures}

Figure 2 (Panel A) depicts the equity market integration patterns generated by the $S C, 1 s t P C$ and $\bar{R}^{2}$ for the three country groups. Our results suggest that the basic $S C$ and the two recently introduced PCA-based measures give rise to almost identical equity market integration dynamics. In the dynamics depicted in Figure 2, the only noteworthy difference between the $S C$ and the two PCA-based measures is that the $\bar{R}^{2}$ tends to suggest a relatively high level of integration. More specifically, for each country group the $\bar{R}^{2}$ is always above 0.5. Differently, the $S C$ and $1 s t P C$ range from a minimum of 0.20 (mid-90's in EMs) to a maximum of 0.85 (subprime crisis period in DMs). In other words, we observe only differences in the magnitude of the degree of integration while the integration trends are almost indistinguishable. We remark that the similarity between the 1 st $P C$ and $\bar{R}^{2}$ should not come as a surprise. By construction, as mentioned in Section 3.2, the percentage of variance explained by the first component and the cross-country average regression R-square yield identical results. We show this empirically (see Table B.1) and theoretically in Appendix B.

Let us remark that the methodology employed to compute the dynamic $\bar{R}^{2}$ slightly differs from the one used in Pukthuanthong and Roll (2009). As a robustness check, we recompute this alternative measure by following the empirical strategy described in Section 7 of Pukthuanthong and Roll (2009). The original $\bar{R}^{2}$ is plotted in Figure A.4 along with $(i)$ the dynamic $S C-$ estimated as described in Section 3.1 - and (ii) Yearly Correlation (i.e., cross-country average correlation estimated during each calendar year using daily returns). We observe almost the same pattern of growing integration over time for each country group. As in Figure 2, the $\bar{R}^{2}$ is - on average - higher than the Yearly Correlation. ${ }^{16}$ An exception is EMs where, over the period 1995-2007, the $\bar{R}^{2}$ and the Yearly Correlation almost overlap (Figure A.4, middle panel). ${ }^{17}$ Once again, the long-run integration patterns reproduced by the $S C$ and $\bar{R}^{2}$ are almost identical.

\footnotetext{
${ }^{16}$ This result is not surprising. In our opinion, this result is partially driven by the fact that the selected PCs explain a relatively large fraction of returns' variation. Pukthuanthong and Roll (2009) draw similar conclusions. In particular, the patterns generated by the mean $\bar{R}^{2}$ and the mean correlation coefficient are very similar. As in our case, we can observe relevant differences only in the magnitude but not in the trend (Figures 4 and 6 in Pukthuanthong and Roll (2009)), regardless of the chosen cohort. Of course, the use of a lower number of PCs has the only effect of reducing such magnitude-gap.

${ }^{17}$ This is at odds with the results presented in Pukthuanthong and Roll (2009). However, they focus on global equity market integration. At the regional level, and in particular among EMs only, the idiosyncratic component may play an important role regardless of the number of PCs used in each regression.
} 
The stochastic interdependence adjustment - implemented by relying on the Ball and Torous (2006) methodology - does not alter much our main results (see Figure 2, Panel B). What we observe are changes in the degree of integration estimated by the three different measures. As expected, the magnitude of these changes tends to be stronger during crisis-periods. In practice, in the presence of crises the stochastic interdependence adjustment lowers our metrics. This is more evident in EMs. In this respect, stochastic interdependence can be interpreted as a Forbes-Rigobon volatility adjustment. Still, over the long-run ASI-adjusted measures, the $S C$ and PCA-based measures deliver very similar integration dynamics.

Figure 3 depicts integration dynamics for DMs, EMs and ALL generated by employing heteroskedasticity-adjusted measures (i.e., Forbes-Rigobon correlation, DCC-GARCH, BEKK, Conditional Beta). Even if adjusted for volatility, the underlying integration trend of all these indicators seems to be similar to the integration patterns depicted in Figure 2 (Figure 3, Panel A). ${ }^{18}$ This shows up more clearly once we plot the trend - extracted via a standard HodrickPrescott filter - of all these heteroskedasticity-adjusted integration indicators (Figure 3, Panel B). In general, integration seems to follow an increasing trend, although with some differences among country-groups. Precisely, we observe an increase in the trend from the mid-1990s and a drop in the post-Lehman period. This supports the stylized facts reported in Figure 1 showing a drop in international trade among countries in the aftermath of the 2007-2009 subprime crisis. From Figures 2 and 3 we can draw the following conclusions. First, the use of both sets of measures does not generate relevant long-run differences in the equity market integration process. This holds across different country-groups. Second, even if the trend is similar, by accounting for volatility a higher degree of heterogeneity among indicators emerges. This is because volatility-adjusted measures, which explicitly capture periods of higher uncertainty, tend to be more volatile than the measures plotted in Figures 2.

Taken together, the results depicted in Figures 2 and 3 suggest the presence of a common equity market integration trend. As aforementioned, all the proposed measures suggest that after slowing down during the crisis-period at the end of the 1990's and the beginning of 2000's the equity market integration picked up again in the period 2004-2008 and flattened (or slightly decreased) in the aftermath of the Lehman brothers' collapse. A battery of robustness checks

\footnotetext{
${ }^{18} \mathrm{An}$ exception is the Conditional Beta. This result confirms that the cross-country beta dynamics heavily depends on the choice of the factor.
} 
Figure 2: Integration Dynamics: Correlation vs. Robust Measures

Panel A

DMs

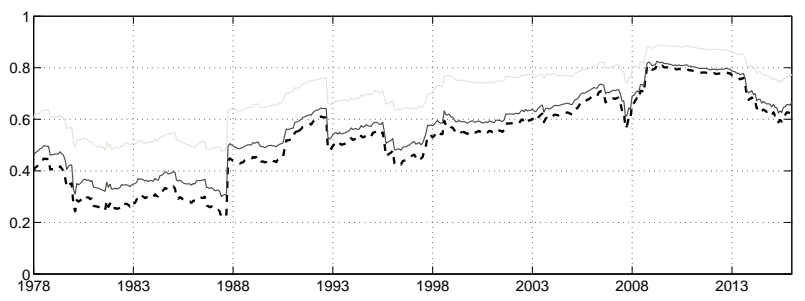

EMs

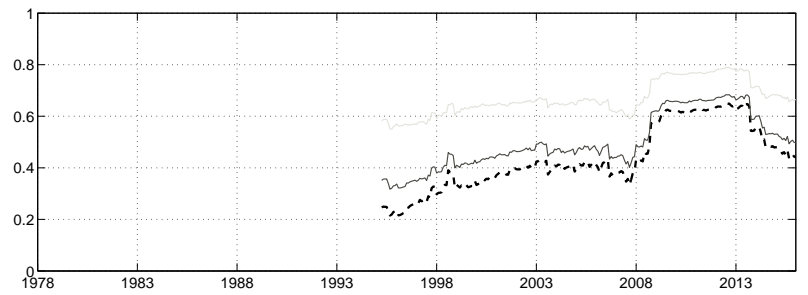

ALL

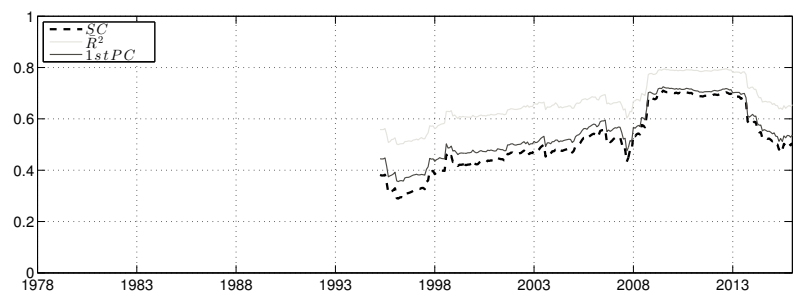

Panel B: ASI

DMs

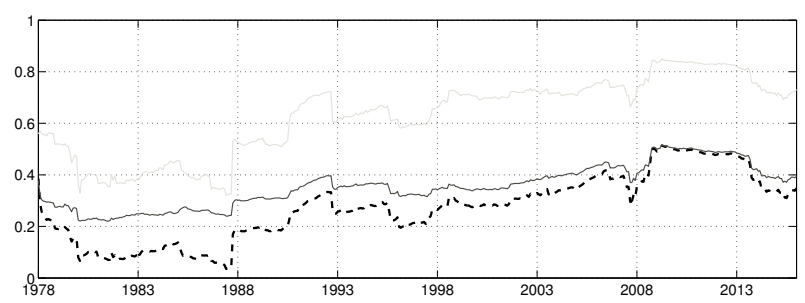

EMs

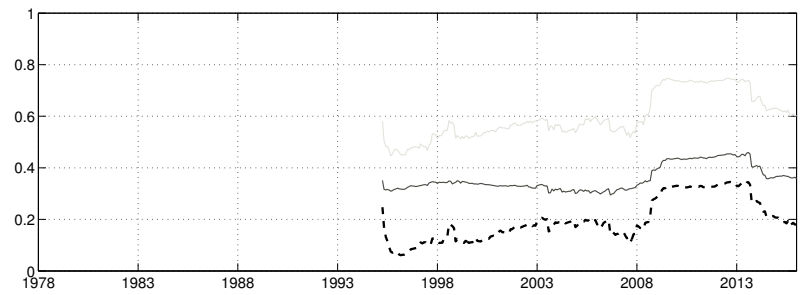

ALL

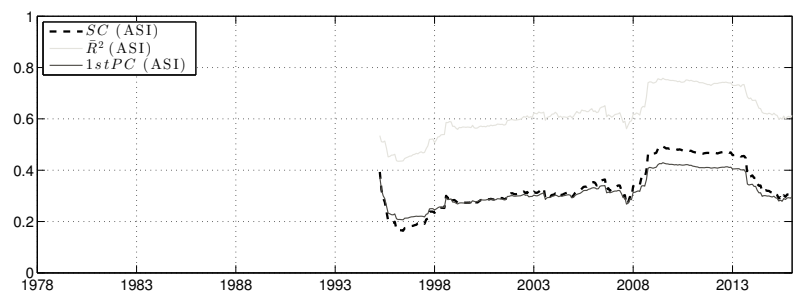

Notes: This figure reports the equity market integration dynamics generated by the $S C$ (dashed black line), $\bar{R}^{2}$ (light gray line) and 1 stPC (dark gray line) for DMs, EMs and ALL. In Panel B, the $S C, \bar{R}^{2}$ and 1 stPC account for stochastic interdependence (ASI) using the model proposed by Ball and Torous (2006). All measures are computed using a rolling window of 60 months. DMs data run from January 1973 to January 2016. EMs data run from May 1990 to January 2016. Source: DGEI.

confirms that the $S C$ and all the other alternative measures give rise to a similar equity market integration trend. All the integration trends obtained from our robustness exercises are reported in Appendix A (Figures A.1, A.2 and A.3). ${ }^{19}$

However, the detected common trend, may not be sufficient to implement effective investment strategies and policies. Therefore, it may be worthwhile to provide a quantitative assessment of the measures' effectiveness in capturing de facto financial integration over time. We attempt to address this issue in the next section.

\footnotetext{
${ }^{19}$ In particular, our results are robust to: $(i)$ different window-lengths (Figure A.1, Panel A (36 windows) and Panel B (96 windows)); (ii) the use of a different number of PCs in computing Volosovych (2011)'s measure (Figure A.2, Panel A); (iii) using the covariance matrix in performing the PCA (Figure A.2), Panel A; $(i v)$ the exclusion of country $c$ equity return in the data matrix employed for computing the PCs serving as regressors in Eq. 2 (Figure A.2, Panel C); $(v)$ using asymmetric specifications in the GARCH models (Figure A.3, Panel B).
} 
Figure 3: Integration Dynamics: Heteroskedasticity-Adjusted Measures

Panel A

DMs

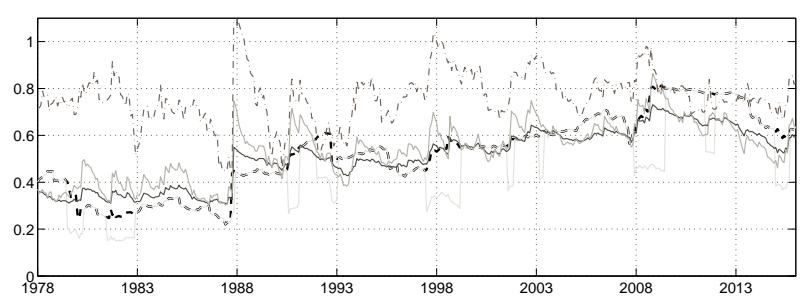

EMs

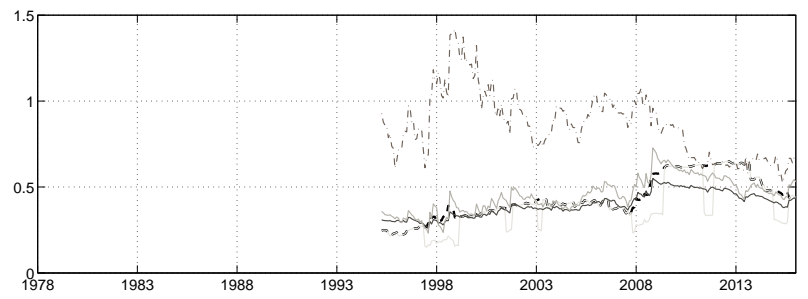

ALL

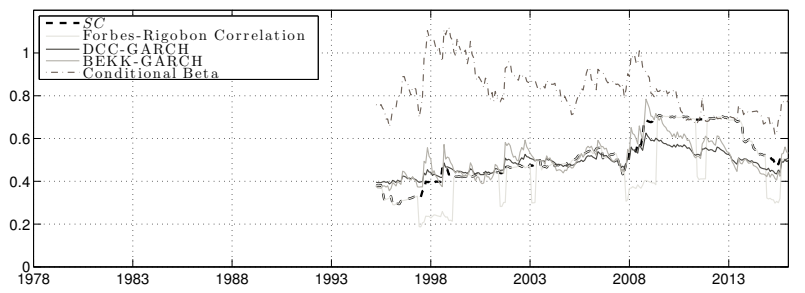

Panel B: HP

DMs

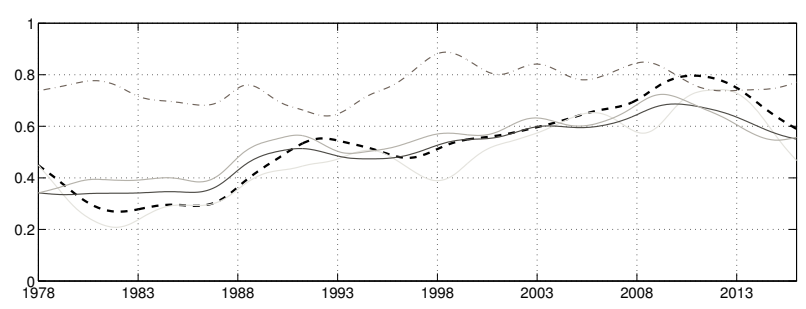

EMs

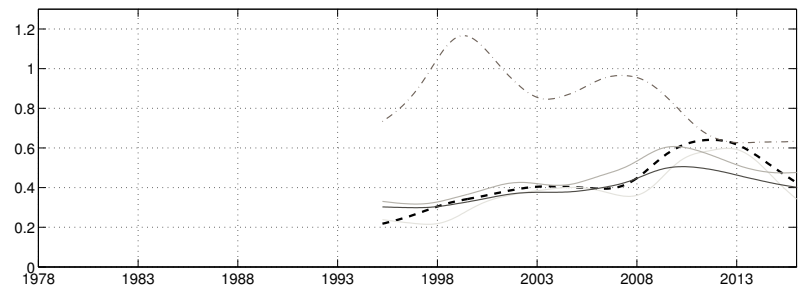

ALL

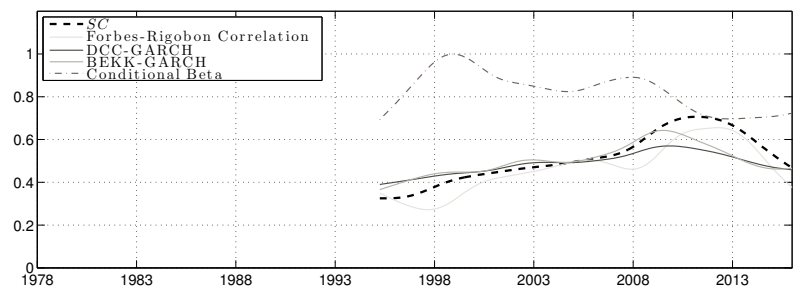

Notes: This figure depicts the equity market integration patterns generated by heteroskedasticity-adjusted measures along with the dynamic $S C$ (dashed black line) for DMs, EMs and ALL. The Forbes-Rigobon correlation is computed using a rolling window of 60 months. DCC-GARCH and BEKK-GARCH are the average bilateral correlation coefficients obtained from applying an ARMA(1,1)-DCC-GARCH and ARMA(1,1)-BEKK-GARCH model, respectively. Conditional Beta is the cross-country average coefficient estimated from Eq. (9). Panel B reports the trend of the equity market integration patterns displayed in Panel A. Trends are obtained via a standard Hodrick-Prescott filter (with $\lambda=14,400$ ). DMs data run from January 1973 to January 2016. EMs data run from May 1990 to January 2016. Source: DGEI.

\section{Ranking Financial Integration Measures}

The debate on whether all these existing measures really capture de facto integration is still open. In this section we aim to evaluate the ability of each measure in capturing integration dynamics by relying on an established international finance result: increasing financial integration leads to declining international portfolio diversification benefits (see, among many others, Longin and Solnik, 1995; Errunza et al., 1999; Driessen and Laeven, 2007; Bekaert et al., 2009; Christoffersen et al., 2012; Donadelli and Paradiso, 2014). We therefore examine whether one measure captures better than another movements in international diversification benefits. ${ }^{20}$

\footnotetext{
${ }^{20}$ We thank two anonymous referees for asking questions that elicited the information in this section.
} 


\subsection{Measuring International Portfolio Diversification Benefits}

A dynamic measure of international portfolio diversification benefits is computed following the methodology described in Christoffersen et al. (2011, 2012). The dynamic measure relies on the concept that correlations are time-varying. As a consequence, diversification benefits also change over time. Let us define first portfolio volatility

$$
\sigma_{P, t} \equiv \sqrt{w^{\prime} \Sigma_{t} w}
$$

Note that the covariance matrix $\Sigma_{t}$ can be decomposed as

$$
\Sigma_{t}=D_{t} \Xi_{t} D_{t}
$$

where $D_{t}$ is a matrix with standard deviations $\sigma_{i, t}$ on the diagonal and zero elsewhere, and $\Xi_{t}$ has ones on the diagonal and correlations off the diagonal. Consider then the extreme case of zero diversification benefits. This implies a correlation matrix $\Xi$ of ones. In this scenario, portfolio volatility reads:

$$
\bar{\sigma}_{P, t} \equiv \sqrt{\omega_{t}^{\prime} D_{t} J_{N \times N} D_{t} \omega_{t}}=\omega_{t}^{\prime} \sigma_{t}
$$

where $J_{N \times N}$ is a $N \times N$ matrix of ones, $\sigma_{t}$ is the vector of individual volatilities at time $t$. The opposite extreme case would lead to a scenario in which each pair of asset returns exhibit perfect negative correlation (i.e., -1). In this case one would be able to find then a portfolio with zero volatility. Using the above portfolio volatility upper and lower bounds, the volatility-based conditional diversification benefit is given by:

$$
V-C D B_{t}=\frac{\bar{\sigma}_{P, t}-\sigma_{P, t}}{\bar{\sigma}_{P, t}}=1-\frac{\sqrt{\omega_{t}^{\prime} \Sigma_{t} \omega_{t}}}{\left(\omega_{t}^{\prime} \sigma_{t}\right)} .
$$

where for the time being $\Sigma_{t}$ is estimated using historical equity market returns. In order to obtain our diversification benefits measure, the portfolio weights $\omega_{t}$ must be defined. In this respect, two approaches can be followed. First, one can select directly the weights that maximize diversification benefits (see Choueifaty and Coignard, 2008). Alternatively, one could construct the minimum variance portfolio in each period and compute diversification benefits associated to the minimum variance portfolio weights. Given the vector of individual volatilities $\sigma_{t}$ and 
the covariance matrix $\Sigma_{t}$ at time $t$, we decide to employ minimum variance portfolio weights $\omega_{t}$ for constructing the international diversification benefits measure. In addition, it is assumed that the weights sum to one and are non-negative.

The dynamics of the $V-C D B$ for DMs, EMs and ALL is depicted in Figure 4. Not surprisingly, for each country group we observe decreasing diversification benefits. This result is in line with Christoffersen et al. $(2011,2012)$ and suggests the presence of a negative relationship between equity market integration and diversification benefits.

\subsection{Financial Integration vs. Diversification Benefits}

To examine the relationship between international portfolio diversification benefits and equity market integration, we employ two basic empirical strategies. First, we compute the average correlation between each of the integration measures plotted in Figures 2 and 3 and the international diversification benefits measure (see Table 2). Second, we regress diversification benefits on each equity market integration measure and a number of control variables (see Tables 3-5). Specifically, we control first for the degree of trade openness (specification (2)) and subsequently for the level of macroeconomic policy uncertainty and bad economic times (specification (3)). Needless to mention, all these factors are associated with the financial integration process. On the one hand, this set of additional macro-economic variables is included to ensure that our market integration coefficients are statistically robust. On the other hand, we do so to purge the market integration coefficient in our regressions from the movements in international trade, economic uncertainty, and bad times (i.e., recessions). ${ }^{21}$ Loosely speaking, the proposed validation approach allows us to identify those integration measures that $(i)$ exhibit a relatively strong (and statistically significant) negative relationship with diversification benefits and ( $i i$ ) capture variations in international diversification benefits rather well. To ensure that our empirical results are not sensitive to the use of the covariance matrix $\Sigma_{t}$ - estimated from raw historical equity returns - our measure of international portfolio diversification benefits is re-computed by accounting for the same heteroskedasticity structure of the employed correlation-based integration measures. ${ }^{22}$ In practice, we use four different approaches to compute $\Sigma_{t}$ : $(i)$ historical

\footnotetext{
${ }^{21}$ Our variable selection is motivated by the work of Volosovych $(2011,2013)$. A similar set of control variables is employed by Kirchner et al. (2010) to examine the transmission mechanism of fiscal policies in the EU over time.

${ }^{22}$ We thank an anonymous reviewer for pointing this out.
} 
Figure 4: Conditional Diversification Benefits

DMs

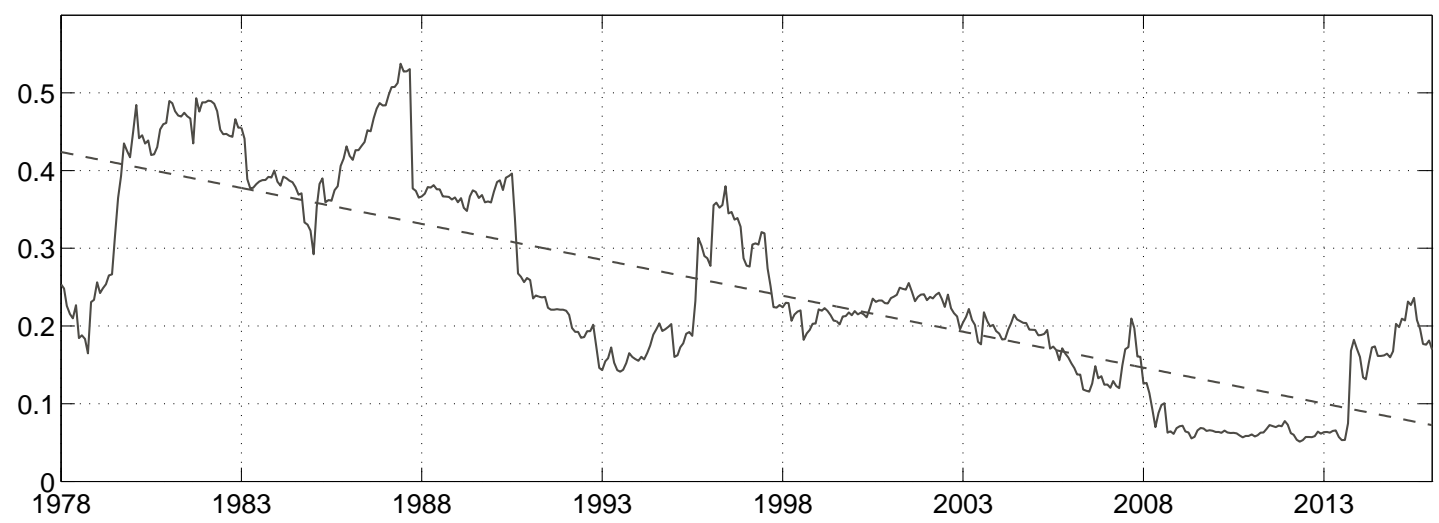

EMs

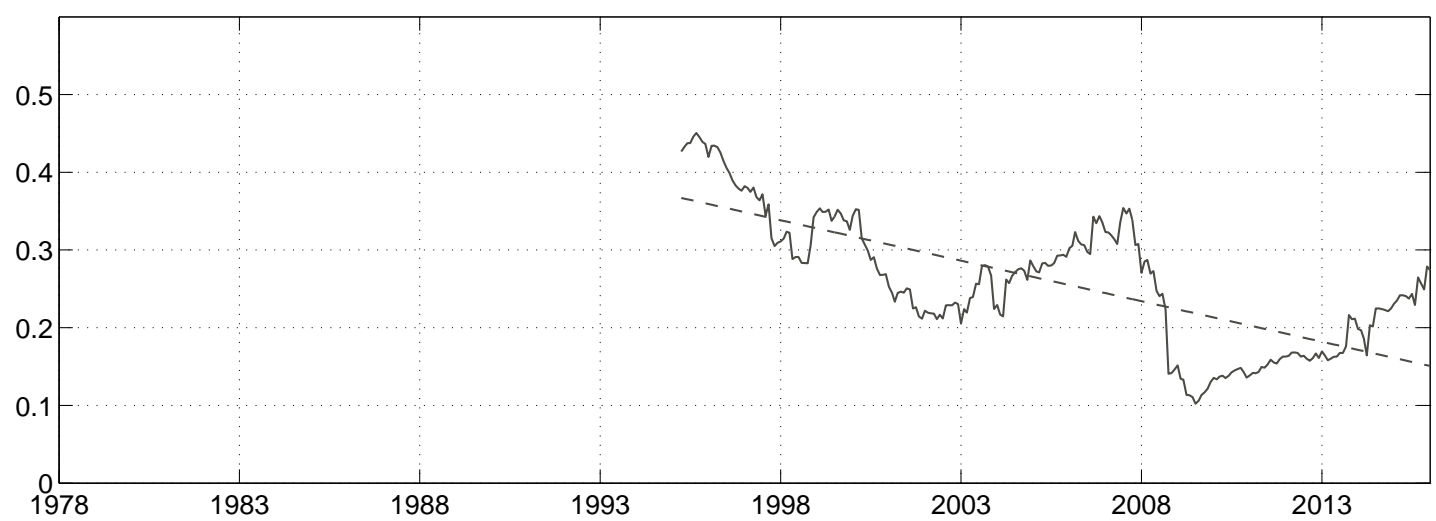

ALL

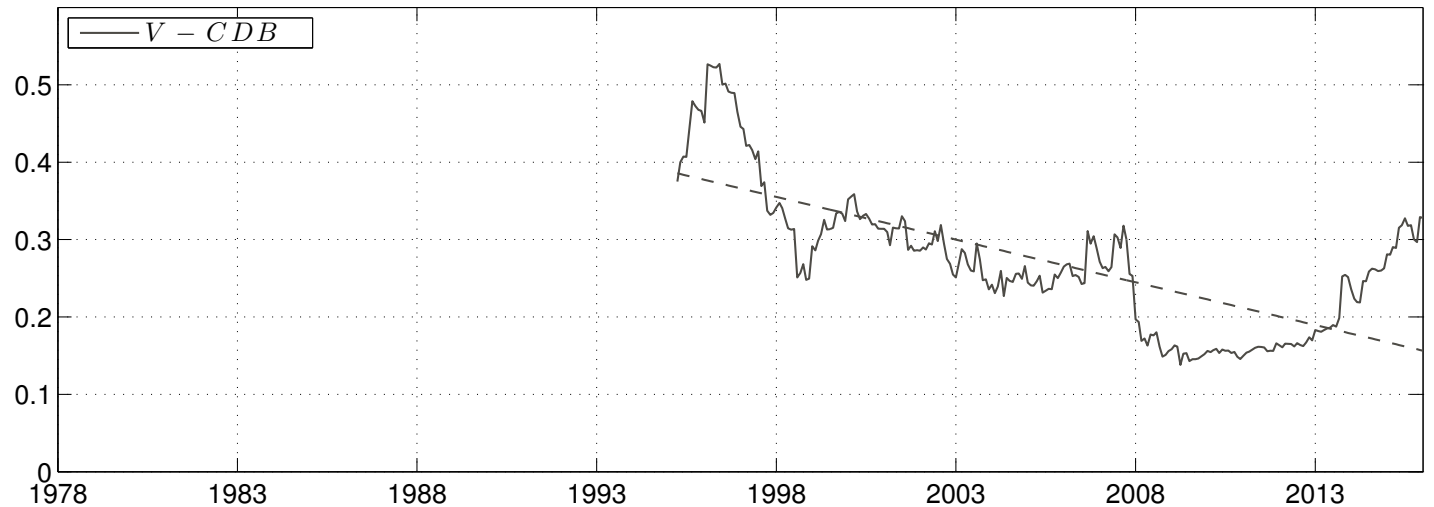

Notes: This figure reports the dynamics of the volatility-based conditional diversification benefits measure for DMs, EMs and ALL. In each country group, $V-C D B$ is computed from monthly country TRIs using a rolling window of 60 months. $\Sigma_{t}$ in Eq. (10) is estimated using historical returns. The dashed line represents the linear trend. DMs data run from January 1973 to January 2016. EMs data run from May 1990 to January 2016. Source: DGEI. 
returns (as assumed in Eq. 10); (ii) ASI; (iii) DCC-GARCH; (iv) BEKK. We therefore obtain three additional "heteroskedasticity-adjusted diversification benefits measures": $V-C D B_{A S I}$, $V-C D B_{D C C}, V-C D B_{B E K K}$. Correlation coefficients (Table 2) and regression estimates (Tables 3-5) are therefore produced using the diversification benefits measures compatible with the same volatility adjustment applied to the integration measure. ${ }^{23}$

Table 2: Integration Indexes vs. Diversification Benefits: Average Correlation

\begin{tabular}{|c|c|c|c|}
\hline \multirow{2}{*}{\multicolumn{4}{|c|}{ 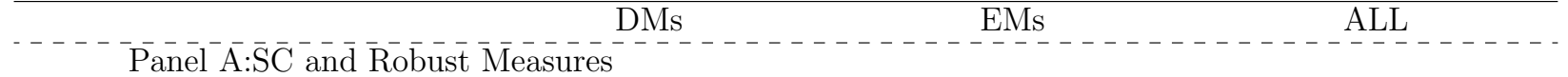 }} \\
\hline & & & \\
\hline $\begin{array}{l}S C \\
\bar{R}^{2}\end{array}$ & $\begin{array}{l}-0.665^{* * *} \\
-0.586 * * *\end{array}$ & $\begin{array}{l}-0.725 \text { * } \\
-0.635^{* * *}\end{array}$ & $\begin{array}{l}-0.085 \\
-0.640 * * *\end{array}$ \\
\hline $1 s t P C$ & $-0.637^{* * *}$ & $-0.721^{* * *}$ & $-0.661^{* * *}$ \\
\hline \multicolumn{4}{|c|}{ Panel B: ASI-Adjusted Measures } \\
\hline $\bar{S} \bar{C} \overline{(A)} \bar{S} \mathrm{I})$ & $-\overline{0} . \overline{6} \overline{6} \overline{6}^{* * \bar{*}}$ & $-0.63 \overline{8}^{* * *}$ & $-\overline{0} . \overline{6} 86^{* \bar{*} *} *^{-}$ \\
\hline $\bar{R}^{2}(\mathrm{ASI})$ & $-0.604^{* * *}$ & $-0.693^{* * *}$ & $-0.633^{* * *}$ \\
\hline $1 s t P C(\mathrm{ASI})$ & $-0.554^{* * *}$ & $-0.568^{* * *}$ & $-0.642^{* * *}$ \\
\hline \multicolumn{4}{|c|}{ Panel C: Heteroskedasticity-Ādjusted Measures } \\
\hline Forbes-Rigobon & $-0.0 \overline{2} \overline{6}$ & -0.060 & -0.009 \\
\hline BEKK & $-0.529^{* * *}$ & $-0.703^{* * *}$ & $-0.576^{* * *}$ \\
\hline DCC & $0.595^{* * *}$ & $0.700^{* * *}$ & $-0.565^{* * *}$ \\
\hline Cond. Beta & $-0.380^{* * *}$ & $0.480^{* * *}$ & $-0.356^{* * *}$ \\
\hline
\end{tabular}

Notes: This table presents the average correlation, based on 5-year rolling windows, between international diversification benefits and integration dynamics depicted in Figures 2 and 3 for DMs, EMs, and ALL. In Panel B (for SC (ASI)), the dynamic international diversification benefits measure is computed by adjusting $\Sigma_{t}$ in Eq. (10) for stochastic interdependence. In Panel C, the dynamic international diversification benefits measure is computed by adjusting $\Sigma_{t}$ in Eq. (10) for heteroskedasticity. All variables are expressed in log-differences. DMs data run from February 1978 to January 2016, EMs and ALL run from May 1995 to January 2016. Significance of $t$-tests for the correlation coefficient at the $10 \%, 5 \%$ and $1 \%$ levels is denoted by $*$, ** and $* * *$.

Entries in Table 2 show that the $S C$ is highly correlated with the conditional international diversification benefits measure. Specifically, the correlation between the $S C$ and diversification benefits is highest (second highest) for EMs (DMs and ALL). Additionally, it is highly statistically significant. Estimates from the regression analyses in Tables 3, 4 and 5 corroborate this result. Firstly, we observe that, with the exception of the Forbes-Rigobon volatility-adjusted measure, all integration indicators exhibit a negative and statistically significant market integration coefficient. This, confirms that an increase in the degree of equity market integration lowers international portfolio diversification benefits. Secondly, entries in Tables 3-5 show that the $S C$ explains - on average - a relatively high percentage of $V-C D B$ variation. In more de-

\footnotetext{
${ }^{23}$ We relate $(i) V-C D B$ with $S C$; $(i i) V-C D B_{A S I}$ with $S C$ (ASI); (iii) $V-C D B_{D C C}$ with $D C C-G A R C H$; and (iv) $V-C D B_{B E K K}$ with BEKK, FR, and Cond.Beta. Note that the use of $\Sigma_{t}$ corrected for the same international events used to compute the Forbes-Rigobon correlation will lead to artificial estimates. For this reason, we relate the Forbes-Rigobon volatility-adjusted correlation with $V-C D B_{B E K K}$. We stress that using $V-C D B_{D C C}$ yields similar results.
} 
tail, the $S C$ exhibits the highest adjusted R-square statistic for the country group ALL (Table 5). For DMs (Table 3) and EMs (Table 4), the performance of the $S C$ is in line with that one of more sophisticated integration measures (i.e., PCA-based and volatility-adjusted measures). ${ }^{24}$

We acknowledge that the computed financial integration and conditional diversification benefits indexes have measurement errors and thus may give rise to weak OLS estimates. To ensure that our estimates are robust enough, we conduct a simulation exercise to examine whether such errors are quantitatively relevant. Overall, results from this test show that the measurement errors embedded in the computed integration indexes and conditional diversification measures do not undermine our estimates. Details on the employed methodology, simulation results and data measurement errors are reported in Appendix D.

To evaluate the performance of our regression models, the pseudo adjusted R-square statistic obtained from GMM estimations is also used. ${ }^{25}$ The $S C$ exhibits - on average - the highest pseudo adjusted R-square. Therefore, GMM estimates confirm our main findings suggesting that the $S C$ represents a good candidate to capture de facto integration. Note also that bootstrapped standard errors - reported in square brackets - do not alter the significance of the market integration coefficients. ${ }^{26}$

We stress that these results hold over time. This is confirmed by the dynamic regression adjusted R-square plotted in Figure E.1 of Appendix E. For the sake of brevity, results are reported for the country group ALL only. Results for the country groups DMs and EMs are qualitatively similar and are available upon request. Our rolling estimates show that the percentage of variation in international diversification benefits explained by the $S C$ and the two robust PCA-

\footnotetext{
${ }^{24}$ We apply the same empirical strategies to examine whether the recent segmentation index developed by Bekaert et al. (2011) performs as well as the proposed integration indexes. Note that in this case equity market segmentation and $V-C D B$ should move in the same direction (i.e., $V-C D B$ rise as segmentation increases). Segmentation indexes, computed along the lines of Bekaert et al. (2011), are plotted in Figure C.1. Additional details on the segmentation index and its ability in capturing de facto integration are reported in Appendix C. The results show that this index is not able to explain the dynamics of international diversification benefits (see Tables C.1 and C.2). In particular, we find (i) a counterfactual negative correlation coefficient between the segmentation index and our measure of international diversification benefits, and (ii) a counterfactual negative (and statistically insignificant) market segmentation coefficient.

${ }^{25}$ As pointed out by Carroll et al. (2011), GMM estimations may be useful in the presence of error measurements. However, under the instrumental variable (IV) variable approach the R-square statistic is not robust. Therefore, we calculate a pseudo adjusted R-square statistic that uses the square correlation between the dependent variable (i.e., international diversification benefits measure) and the fitted value of the dependent variable.

${ }^{26}$ If only $V-C D B$ or $V-C D B^{*}$ is used in our validation exercise, similar correlation coefficients and regression estimates are obtained. For space considerations, all the results for these robustness experiments are not reported but are available upon request.
} 
based measures $\left(\bar{R}^{2}\right.$ and 1 stPC) is very similar over time (Figure E.1, Panel A). This holds for the SI-adjusted $\bar{R}^{2}$ and 1stPC (Figure E.1, Panel B). Differently, heteroskedasticity-adjusted measures tend to explain a lower percentage of diversification benefits variation (Figure E.1, Panel C). This performance gap is - on average - larger after the second half of 2000s.

To shed further robustness on our main results, we adopt the general-to-specific (Gets) variable selection approach described in Hendry and Krolzig (2003, 2005) and Krolzig (2008). Specifically, we apply this approach to a regression where the dependent variable represents a synthesis of all diversification benefits measures (i.e., the first PC extracted from the four different reproduced dynamic diversification benefits measures, $\left.V-C D B^{*}\right)$ and the explanatory variables are represented by all the computed integration indicators. After having specified a general unrestricted model including all the potential candidate variables able to explain a target variable $\left(V-C D B^{*}\right)$, the algorithm implements a multi-path search aimed at eliminating all the "irrelevant variables". The advantage of using this procedure is that it is able to handle high collinearity among regressors (Hendry and Krolzig, 2005). The results obtained from this procedure - reported in Appendix E (see Table E.1) - confirm that $S C$ is the most significant variable in explaining diversification benefits' dynamics. Its coefficient is highly statistically significant and, as expected, negative. As suggested by Figure E.2, this holds across the full sample. Specifically, we observe that the Gets procedure always selects as "best" integration measure the $S C$. The attached market integration coefficient is always negative and highly significant. ${ }^{27}$

\footnotetext{
${ }^{27}$ As a final robustness check, we propose an alternative validation exercise. This relies on the empirical regularities suggesting that increasing integration improves trade and financial openness (see Figure 1). Financial integration lowers the cost of capital, raises cross-country investment opportunities, and provides a more efficient international allocation of capital. This, of course, facilitates FDI. In practice, we regress FDI on the reproduced integration patterns. To some extent this additional exercise ensures that our main findings do not rely on the choice of priced-based indicators as unique integration-driven phenomena. Estimation results are reported in Appendix F. Entries in Table F.1 corroborate our main finding. The $S C$ captures movements in international investments better than the $1 s t P C, \bar{R}^{2}$ and heteroskedasticity adjusted measures. For brevity's sake, we report in Table F.1 only the results for the country group ALL. For DMs and EMs, results are very similar and are available upon request.
} 


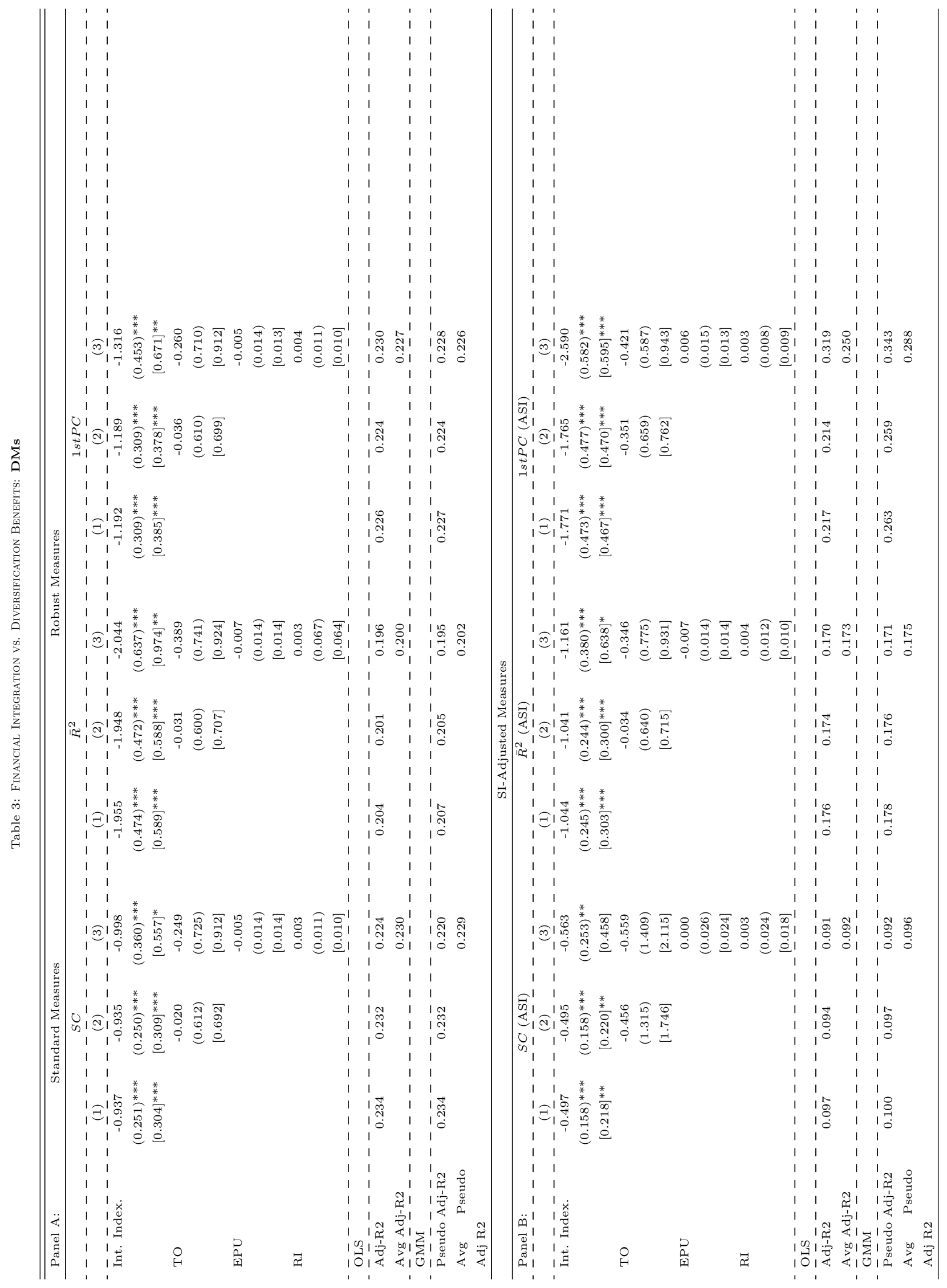




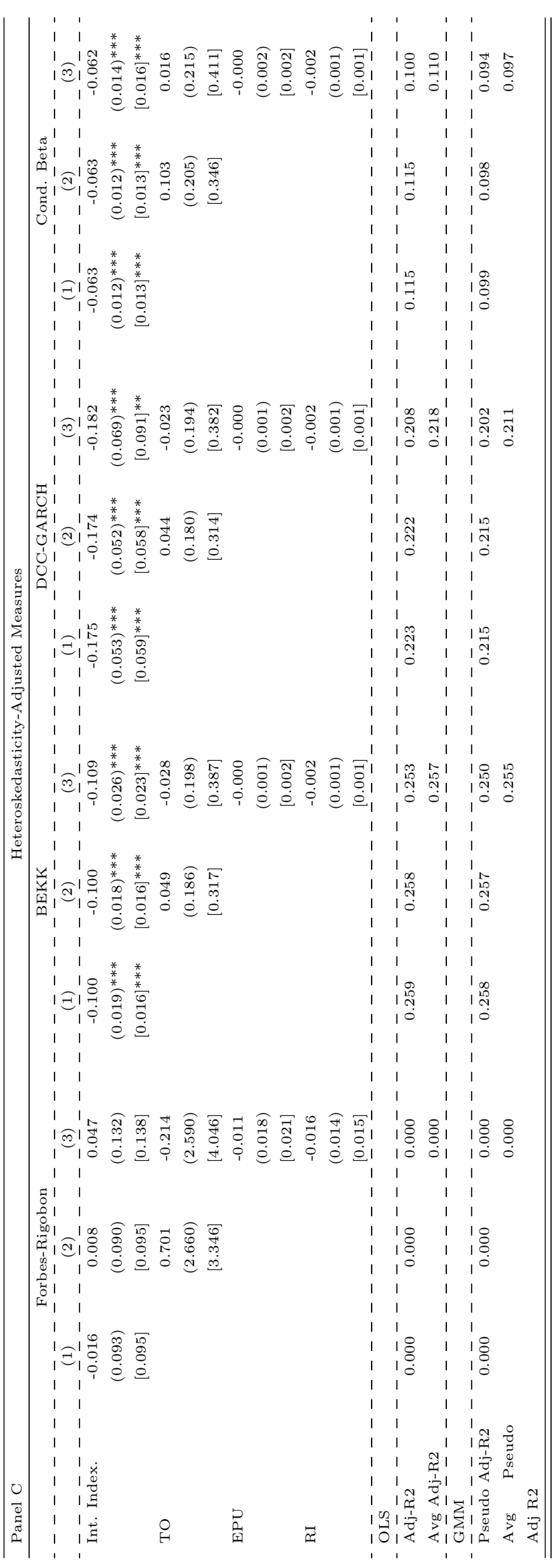

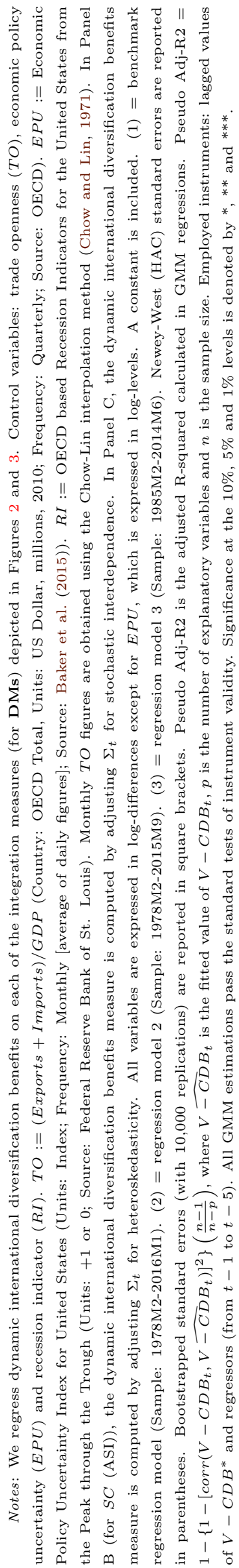




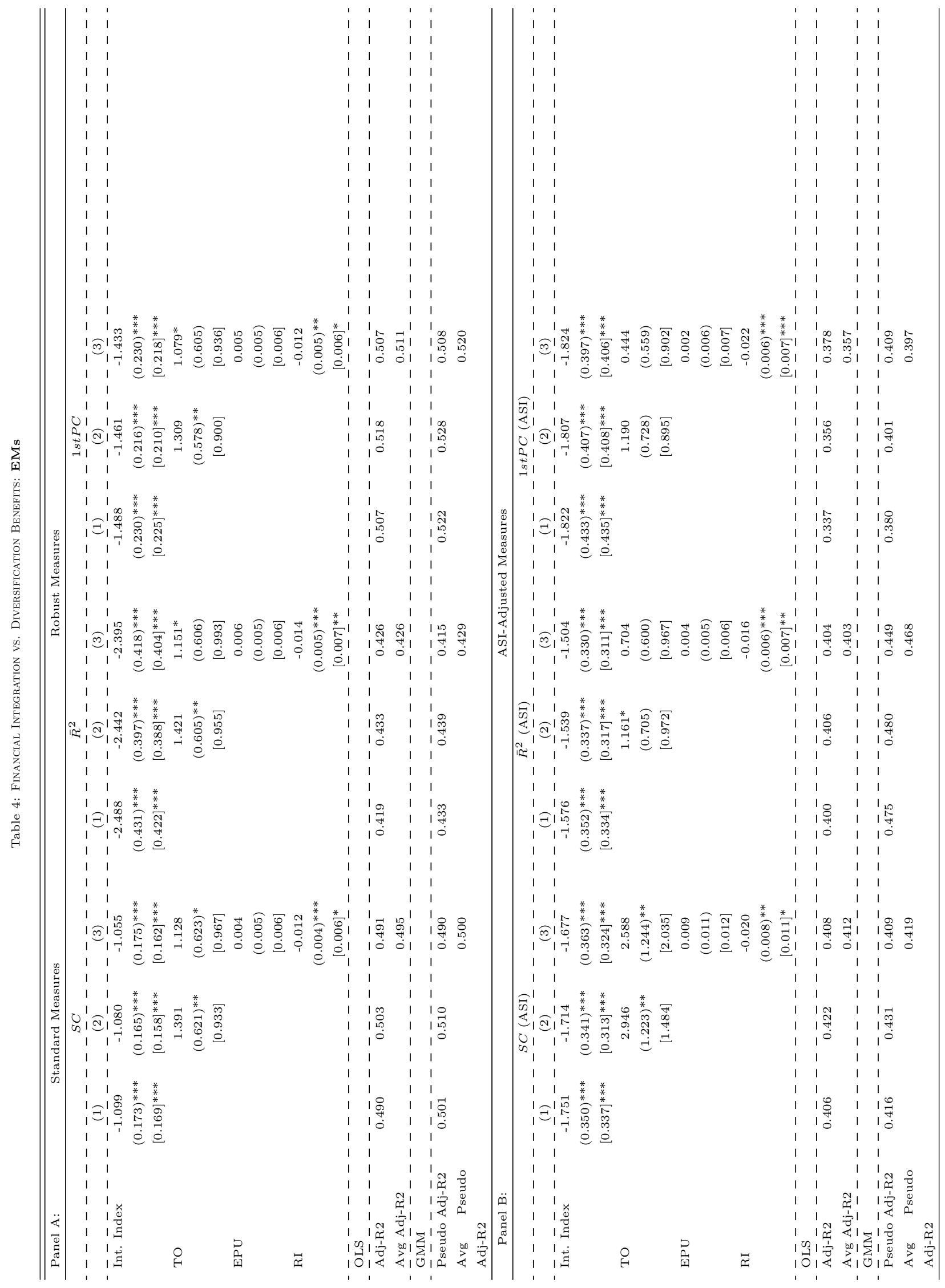



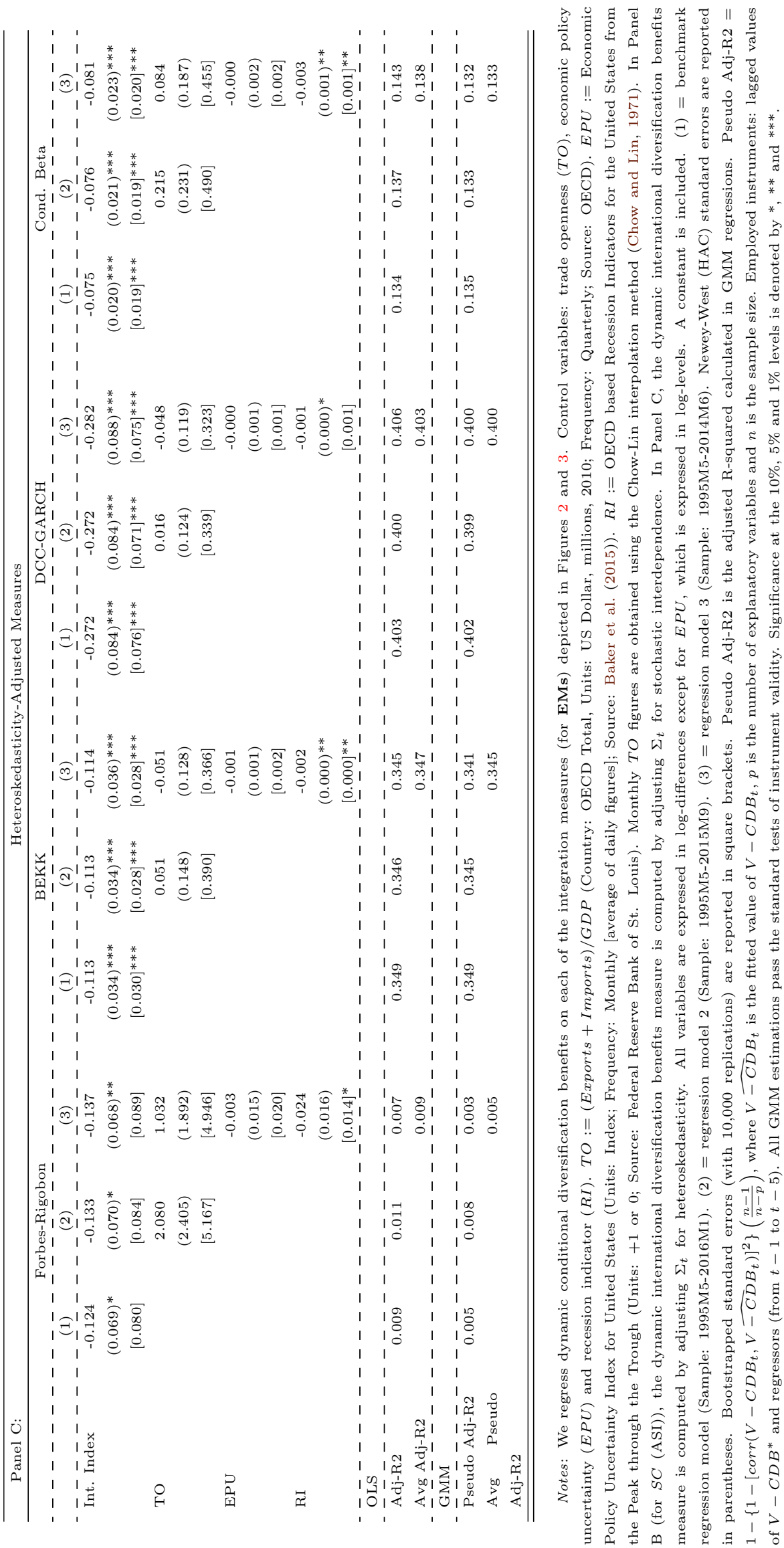


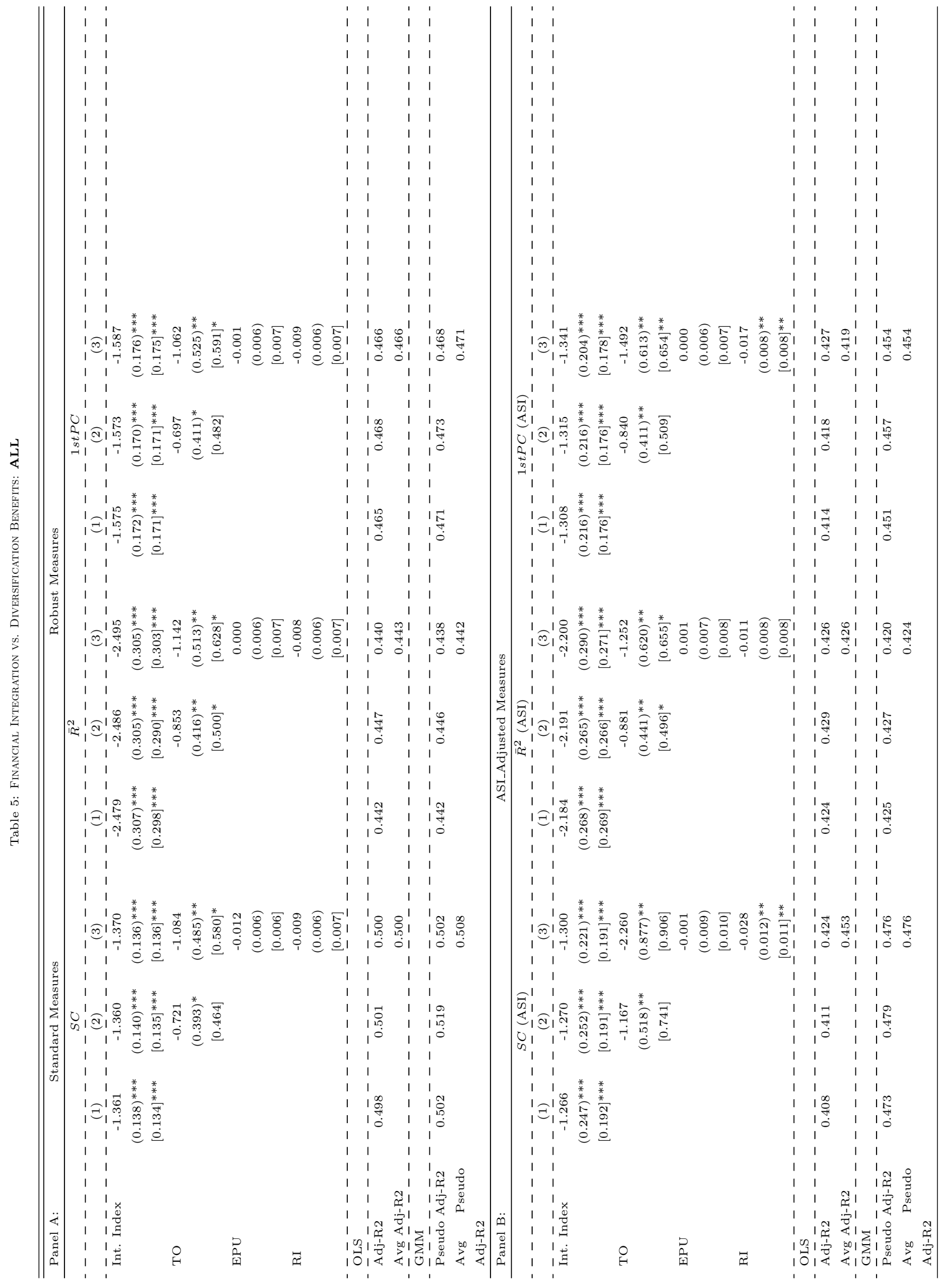




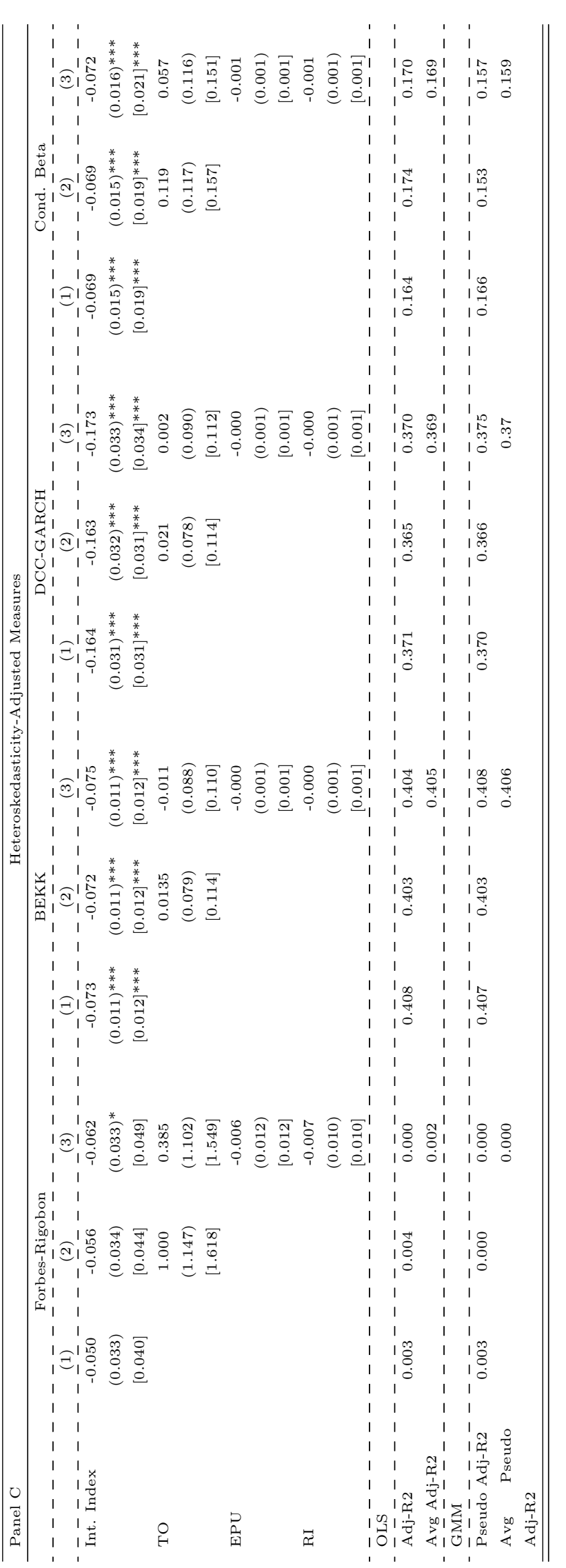

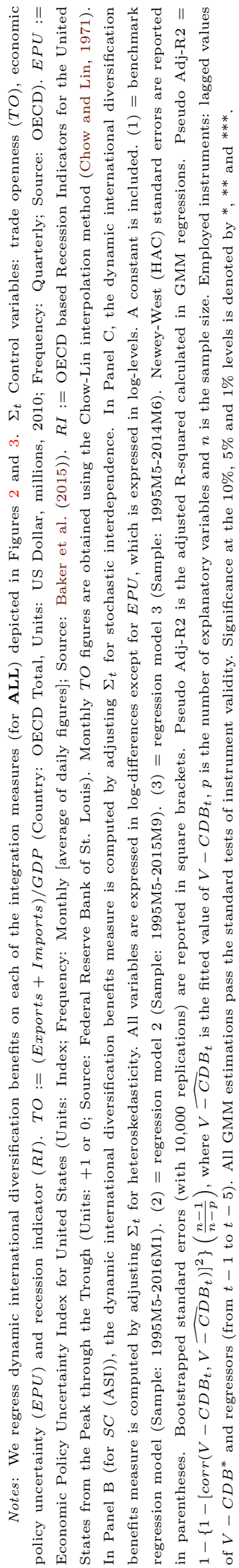




\section{SC vs. Alternative Measures: Additional Discussions}

The results reported in the previous sections suggest that the $S C$ does not fail to capture regional and global equity market integration. Actually, we observe that the $S C$ can act as a substitute for the two recently introduced PCA-based integration measures (i.e., $\bar{R}^{2}$ and $1 s t P C$ ) and a number of widely used heteroskedasticity-adjusted indicators (i.e., Forbes-Rigobon correlation, DCC-GARCH, BEKK, Cond. Beta).

Our findings do not imply that $S C$ represents the best and most robust measure. All measures, of course, have their strengths and weaknesses. Volatility- and heteroskedasticityadjusted indicators, for instance, tend to provide highly volatile integration patterns. However, they do relatively well in capturing periods of high uncertainty (e.g., financial crises). Thus, for short-run analyses, it might be more appropriate to employ heteroskedasticity-adjusted measures. Nevertheless, this departs from the goal of measuring long-run equity market integration trends.

As most correlation-based measures,${ }^{28}$ the two PCA-based measures have an upper bound of one. This suggests that as they approach one full equity market integration is detected. In addition, similarly to the $S C$, Forbes-Rigobon correlation, DCC-GARCH and BEKK do not rely on the choice of a benchmark country. Note also that the $\bar{R}^{2}$ and 1 stPC, as all the correlation-based measures, represent price-based measures. As discussed in Section 2, this implies their reliance on historic price data, which tend to be available for a larger variety of countries, regions and industries, and have a better quality than data on international capital flows generally used to construct quantity-based measures (see Obstfeld and Taylor, 2004).

PCA-based indicators may also have a clear theory-based interpretation. In this respect, Volosovych $(2011,2013)$ argues that the first principal component extracted from a data matrix composed by countries' long-term bond yields serves as a proxy for the world interest rate. Similarly, Pukthuanthong and Roll (2009) point out that the first 10 PCs extracted from a data matrix composed by countries' equity returns may proxy the 10 largest industries. Regardless the debate of the existence of a world interest rate, it is unclear to what extent these interpretations can be generalized. The first component extracted from countries' equity returns may

\footnotetext{
${ }^{28}$ An exception is the conditional beta, which is not bounded. For this reason, it does not provide a clear-cut interpretation about the degree of equity market integration.
} 
or may not be regarded as the word equity return and the choice of the number of countries is at the discretion of the researcher. For instance, Volosovych (2011) extracts the first component from only 11 countries, whereas including more countries might be more appropriate for his interpretation. Also, Pukthuanthong and Roll (2009)'s choice of the number of PCs to be used as global factors in countries' regressions is somehow arbitrary. Furthermore, differently from standard asset pricing model, the $\bar{R}^{2}$ relies on non-traded risk factors (i.e., artificial factors) while global macro-factors or traded financial risk factors are ignored. Admittedly, both PCA-based measures rely on subjective choices.

The theoretical justifications provided to build the $\bar{R}^{2}$ and 1 stPC are comprehensible. On the one hand, from a theoretical point of view, it is true that two countries can exhibit simultaneously a low correlation but a high $\bar{R}^{2}$. On the other hand, however, as global goods and financial markets openness rises, returns tend to be driven by similar global factors. It is, thus, very likely that a number of global factors (and in particular principal components extracted from a data matrix composed by international countries' returns) will comove with most countries' returns in a similar way, both qualitatively and quantitatively (as suggested by our empirical findings).

What emerges from our analysis is simply that the widely used heteroskedasticity-adjusted, the two recently introduced robust measures of integration, and the $S C$ give rise to a very similar long-run equity market integration trend. Put differently, all these measures tend to provide similar information on the regional and global equity market integration processes. Further, we observe that the $S C$ explains - on average - variations in integration-driven phenomena better than all the other proposed measures. If a Gets reduction procedure is employed, then the $S C$ results to be the best candidate to explain movements in diversification benefits (see Appendix E).

The question one may pose is then the following: why should we use alternative and more sophisticated measures if the $S C$ provides very similar information on the shape of the integration process? Differences in the set of information provided by different measures become negligible in particular over the long-run and if a relatively large number of countries is employed in the analysis. Our view here is that the $S C$ and all the other proposed measures capture somehow cross-country equity market returns' comovement. The $S C$, of course, serves this purpose quite well. In addition, as opposed to all the other measures, it requires low computational effort. 
There is a number of directions in which this work could be fruitfully extended. First, novel measures that do not rely on comovement should be developed. In this respect, recent methodologies - based on Granger-causality - employed to capture systemic risk might be used as a benchmark (see Billio et al., 2012). Second, theory-based validation schemes to rank different integration measures should be taken into account in future research. Finally, our empirical analysis could be extended to other asset classes (e.g., bonds, commodities).

\section{Concluding Remarks}

Changes in the degree of integration among international equity markets affect the decisions of policymakers, investors and households. Therefore, measuring financial integration and understanding its evolution over time is of general interest. As there are many possible measures of financial integration, it is natural to ask whether they all provide similar information. To this end, we compare and evaluate the financial integration patterns produced by a battery of different indicators. In particular, to account for all possible dimensions of integration, we rely on: $(i)$ the $S C$; $(i i)$ two PCA-based measures and (iii) several heteroskedasticity-adjusted measures. Three novel indicators are also introduced: $(i)$ a volatility-adjusted measure relying on main international financial and political crisis episodes and (ii) two PCA-based measures adjusted for stochastic interdependence. Moreover, to ensure that our results are robust with respect to the chosen sample, integration is investigated for three different country groups: DMs, EMs and ALL (i.e., a group of economies with a large variety of sizes and degrees of openness). Results, for all country-groups, suggest that all measures exhibit a very similar long-run equity market integration trend. Specifically, we observe that $(i)$ the $S C$ and the two PCA-based measures give rise to nearly identical equity market integration dynamics and (ii) heteroskedasticity-adjusted measures, due to the presence of crises, tend to produce more volatile patterns. Taken together, the reproduced dynamics suggest that the $S C$ and all the other proposed measures provide similar information about the integration process.

To evaluate the performance of the proposed indicators in capturing de facto integration, we link each of the produced integration patterns with a dynamic measure of international diversification benefits. Our statistical results suggest that the $S C$ performs as well or better than more sophisticated measures (i.e., $\bar{R}^{2}$, 1 st $P C$ and volatility-adjusted measures). It turns 
out that the dynamic $S C$ captures de facto integration rather well. Said differently, if one aims to understand the shape of the equity market integration process over the long-run and is restricted by mathematical complexity or computational power, then he is well advised to use the $S C$. 


\section{References}

Abad, P., Chuliá, H., Gómez-Puig, M., 2010. EMU and European government bond market integration. Journal of Banking and Finance 34, 2851-2860.

Adam, K., Jappelli, T., Menichini, A., Padula, M., Pagano, M., 2002. Analyse, compare, and apply alternative indicators and monitoring methodologies to measure the evolution of capital market integration in the European Union. University of Salerno, Studies in Economics and Finance (CSEF) .

Baca, S. P., Garbe, B. L., Weiss, R. A., 2000. The rise of sector effects in major equity markets. Financial Analysts Journal 56, 34-40.

Baker, S. R., Bloom, N., Davis, S. J., 2015. Measuring economic policy uncertainty. NBER Working Paper No. 21633 .

Ball, C. A., Torous, W. N., 2006. Contagion in the presence of stochastic interdependence. Mimeo .

Barr, D., Priestley, R., 2004. Expected returns, risk and the integration of international bond markets. Journal of International Money and Finance 23, 71-97.

Bekaert, G., Harvey, C. R., Lundblad, C. T., Siegel, S., 2011. What segments equity markets? Review of Financial Studies 24, 3847-3890.

Bekaert, G., Hodrick, R., Zhang, X., 2009. International stock return comovements. Journal of Finance 64, 2591-2626.

Bekiros, S. D., 2013. Contagion, decoupling and the spillover effects of the us financial crisis: Evidence from the BRIC markets. International Review of Financial Analysis 33, 58-69.

Billio, M., Getmansky, M., Lo, A. W., Pelizzon, L., 2012. Econometric measures of connectedness and systemic risk in the finance and insurance sectors. Journal of Financial Economimics 104, 535-559.

Blanchard, O., Dell'Ariccia, G., Mauro, P., 2010. Rethinking macroeconomic policy. Journal of Money, Credit and Banking 42, 199-215. 
Bollerslev, T., 1990. Modelling the coherence in short run nominal exchange rates: A multivariate generalized ARCH model. Review of Economics and Statistics 72, 498-505.

Brooks, R., Negro, M. D., 2004. The rise in comovement across national stock markets: Market integration or IT bubble? Journal of Empirical Finance 11, 659-680.

Caporale, G. M., Spagnolo, N., 2011. Stock market integration between three CEECs, Russia, and the UK. Review of International Economics 19, 158-169.

Carrieri, F., Errunza, V., Hogan, K., 2007. Characterizing world market integration through time. Journal of Financial and Quantitative Analysis 42, 915-940.

Carroll, C. D., Otsuka, M., Slacalek, J., 2011. How large are housing and financial wealth effects? A new approach. Journal of Money, Credit and Banking 43, 55-79.

Chiang, T. C., Jeon, B. N., H, L., 2007. Dynamic correlation analysis of financial contagion: Evidence from Asian markets. Journal of International Money and Finance 26, 1206-1228.

Choudhry, T., Jayasekera, R., 2013. Level of efficiency in the UK equity market: Empirical study of the effects of the global financial crisis. Review of Quantitative Finance and Accounting $44,213-242$.

Choueifaty, Y., Coignard, Y., 2008. Toward maximum diversification. Journal of Portfolio Management $35,40-51$.

Chow, G. C., Lin, A. L., 1971. Best linear unbiased interpolation, distribution, and extrapolation of time series by related series. Review of Financial Studies 53, 372-375.

Christoffersen, P., Errunza, V., Kris, J., Langlois, H., 2011. Is the potential for international diversification disappearing? Working Paper .

Christoffersen, P., Errunza, V., Kris, J., Langlois, H., 2012. Is the potential for international diversification disappearing? A dynamic copula approach. Review of Financial Studies 25, $3711-3751$.

Colacito, R., Croce, M. M., 2010. The short- and long-run benefits of financial integration. American Economic Review: P\&P 100, 527-531. 
Connolly, R. A., Stivers, C., Sunc, L., 2007. Commonality in the time-variation of stock-stock and stock-bond return comovements. Journal of Financial Markets 10, 192-218.

Cunningham, A., Eklund, J., Jeffery, C., Kapetanios, G., Labhard, V., 2012. A state space approach to extracting the signal from uncertain data. Journal of Business \& Economic Statistics 30, 173-180.

de Jong, F., de Roon, F. A., 2005. Time varying market integration and expected returns in emerging markets. Journal of Financial Economics 78, 583-613.

De Santis, G., Gérard, B., 1998. How big is the premium for currency risk? Journal of Financial Economics 49, $375-412$.

Donadelli, M., Paradiso, A., 2014. Is there heterogeneity in financial integration dynamics? Evidence from country and industry emerging market equity indexes. Journal of International Financial Markets, Institutions and Money 32, 184-218.

Driessen, J., Laeven, L., 2007. International portfolio diversification benefits: Cross-country evidence from a local perspective. Journal of Banking \& Finance 31, 1693 - 1712.

Egert, B., Kocenda, E., 2011. Time-varying synchronization of European stock markets. Empirical Economics 40, 393-407.

Elyasiani, E., Wanli, Z., 2008. International interdependence of an emerging market: The case of Iran. Applied Economics 40, 395-412.

Engle, R. F., 2002. Dynamic conditional correlation: A simple class of multivariate generalized autoregressive conditional heteroscedasticity models. Journal of Business and Economic Statistics 20, 339-350.

Engle, R. F., Kroner, K. F., 1995. Multivariate simultaneous generalized ARCH. Econometric Theory 11, 122-150.

Engle, R. F., Sheppard, K., 2001. Long-term global market correlations. NBER Working Paper No. 8554. . 
Errunza, V., Hogan, K., Hung, M.-W., 1999. Can the gains from international diversification be achieved without trading abroad? The Journal of Finance 54, 2075-2107.

Forbes, K. J., Rigobon, R., 2002. No contagion, only interdependence: Measuring stock market comovements. Journal of Finance 57, 2223-2261.

Goetzmann, W., Li, L., Rouwenhorst, G., 2005. Long-term global market correlations. Journal of Business 71, 1-38.

Gupta, R., Guidi, F., 2012. Cointegration relationship and time varying co-movements among Indian and Asian developed stock markets. International Review of Financial Analysis 21, $10-22$.

Hendry, D. F., Krolzig, H.-M., 2003. New developments in automatic general-to-specific modelling. Econometrics and the Philosophy of Economics pp. 379-419.

Hendry, D. F., Krolzig, H.-M., 2005. The properties of automatic gets modelling. The Economic Journal 115, C32-C61.

Hilliard, J. E., 1979. The relationship between equity indices on world exchanges. The Journal of Finance 34, 103-114.

Horvath, R., Petrovski, D., 2013. International stock market integration: Central and South Eastern Europe compared. Economic Systems 37, 81-91.

Jappelli, T., Pistaferri, L., 2011. Financial integration and consumption smoothing. The Economic Journal 121, 678-706.

Jayasinghe, P., Tsui, A. K., Zhang, Z., 2014. New estimates of time-varying currency betas: A trivariate BEKK approach. Economic Modelling 42, 128-139.

Jayasuriya, S. A., 2011. Stock market correlations between china and its emerging market neighbors. Emerging Markets Review 12, 418-431.

Jong, J.-C., Kotz, S., 1999. On a relation between principal components and regression analysis. The American Statistician 53, pp. 349-351. 
Kearney, C., Lucey, B. M., 2004. International equity market integration: Theory, evidence and implications. International Review of Financial Analysis 13, 571-583.

Khalid, A. M., Kawai, M., 2003. Was financial market contagion the source of economic crisis in Asia? evidence using a multivariate VAR model. Journal of Asian Economics 14, 131 156.

Kim, S.-J., Moshirian, F., Wu, E., 2006. Evolution of international stock and bond market integration: Influence of the European Monetary Union. Journal of Banking and Finance 30, $1507-1534$.

King, M., Sentana, E., Wadhwani, S., 1994. Volatility and links between national stock markets. Econometrica 62, pp. 901-933.

Kirchner, M., Cimadomo, J., Hauptmeier, S., 2010. Transmission of government spending shocks in the Euro Area: Time variation and driving force. ECB Working Paper n. 1219

Koedijk, K. G., Kool, C. J., Schotman, P. C., van Dijk, M. A., 2002. The cost of capital in international financial markets: Local or global? Journal of International Money and Finance 21, 905 - 929, international Financial Integration.

Krolzig, H., 2008. Gets model selection with sign restrictions. Tech. rep., Working paper, University of Kent, Canterbury. Presented at the ESEM.

Laopodis, N. T., 2011. Equity prices and macroeconomic fundamentals: International evidence. Journal of International Financial Markets, Institutions and Money 21, 247 - 276.

Longin, F., Solnik, B., 1995. Is the correlation in international equity returns constant: 19601990? Journal of International Money and Finance 14, 3-26.

Longin, F., Solnik, B., 2001. Extreme correlation of international equity markets. The Journal of Finance 56, 649-676.

Mauro, P., Sussman, N., Yafeh, Y., 2002. Emerging markets spreads: Then versus now. Quarterly Journal of Economics 115, 695-733. 
McAvoy, G. E., 1998. Measurement models for time series analysis: Estimating dynamic linear errors-in-variables models. Political Analysis 7, 165-186.

Meric, I., Meric, G., 1989. Potential gains from international portfolio diversification and intertemporal stability and seasonality in international stock market relationships. Journal of Banking \& Finance 13, $627-640$.

Morana, C., Beltratti, A., 2008. Comovements in international stock markets. Journal of International Financial Markets, Institutions and Money 18, 31-45.

Nellis, J., 1982. A principal components analysis of international financial integration under fixed and floating exchange rate regimes. Applied Economics 14, 339-354.

Obstfeld, M., Taylor, A., 2004. Global capital markets: Integration, crisis, and growth. Cambridge University Press, New York/ Cambridge. .

Panton, D. B., Lessig, V. P., Joy, O. M., 1976. Comovement of international equity markets: A taxonomic approach. The Journal of Financial and Quantitative Analysis 11, pp. 415-432.

Pukthuanthong, K., Roll, R., 2009. Global market integration: An alternative measure and its application. Journal of Financial Economics 94, 214-232.

Quinn, D. P., Voth, H.-J., 2008. A century of global equity market correlations. American Economic Review 98, 535-40.

Ramchand, L., Susmel, R., 1998. Volatility and cross correlation across major stock markets. Journal of Empirical Finance 5, 397 - 416.

Suzuki, Y., 2014. Financial integration and consumption risk sharing and smoothing. International Review of Economics and Finance 29, 585-598.

Volosovych, V., 2011. Measuring financial market integration over the long run: Is there a U-shape? Journal of International Money and Finance 30, 15351561.

Volosovych, V., 2013. Learning about financial market integration from principal components analysis. CESifo Economic Studies 59, 360-391. 
Wang, P., Moore, T., 2008. Stock market integration for the transition economies: Time-varying conditional correlation approach. The Manchester School 7, 116-133.

Watson, J., 1980. The stationarity of inter-country correlation coefficients: A note. Journal of Business Finance and Accounting 7, 297-303.

Yu, C., 2015. Evaluating international financial integration in a center-periphery economy. Journal of International Economics 95, 129-14.

Yu, I.-W., Fung, K.-P., Tam, C.-S., 2010. Assessing financial market integration in Asia - equity markets. Journal of Banking and Finance 34, 2874-2885. 


\section{A Robustness Checks}

Figure A.1: Equity Market Integration Patterns: Robustness Checks

Panel A: 36-RW

DMs

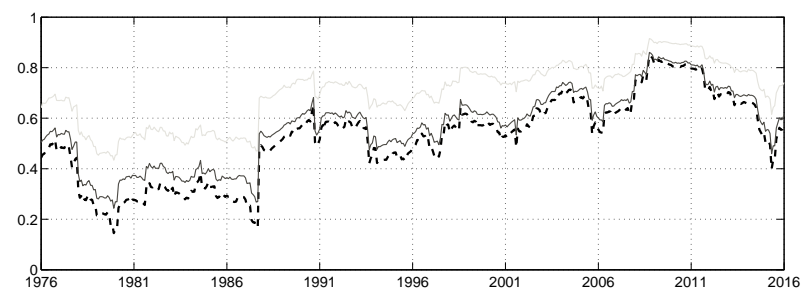

EMs

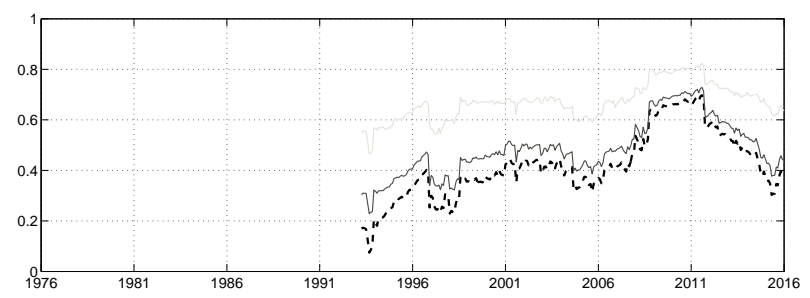

ALL

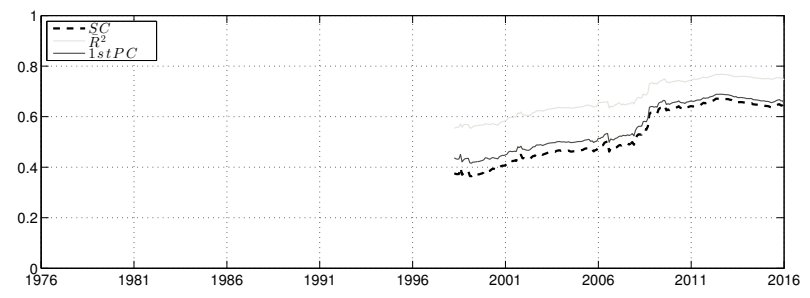

Panel B: 96-RW

DMs

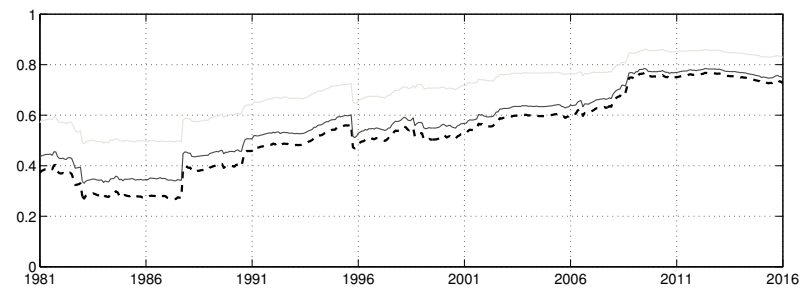

EMs

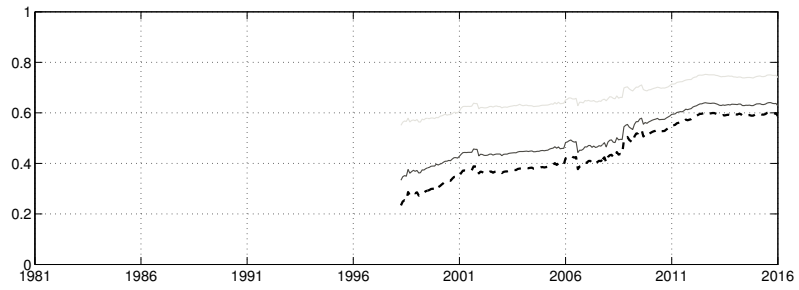

ALL

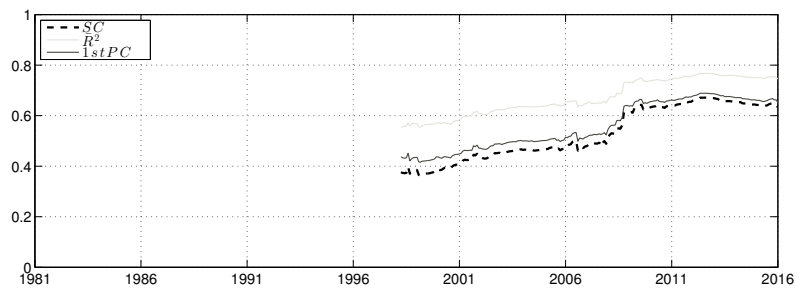

Notes: This figure reports the equity market integration dynamics generated by the $S C$ (dashed black line), $\bar{R}^{2}$ (light gray line) and 1stPC (dark gray line) for DMs, EMs and ALL. All measures are estimated using a rolling window of 36 months (Panel A) and 96 months (Panel B). DMs data run from January 1973 to January 2016. EMs data run from May 1990 to January 2016. Source: DGEI. 


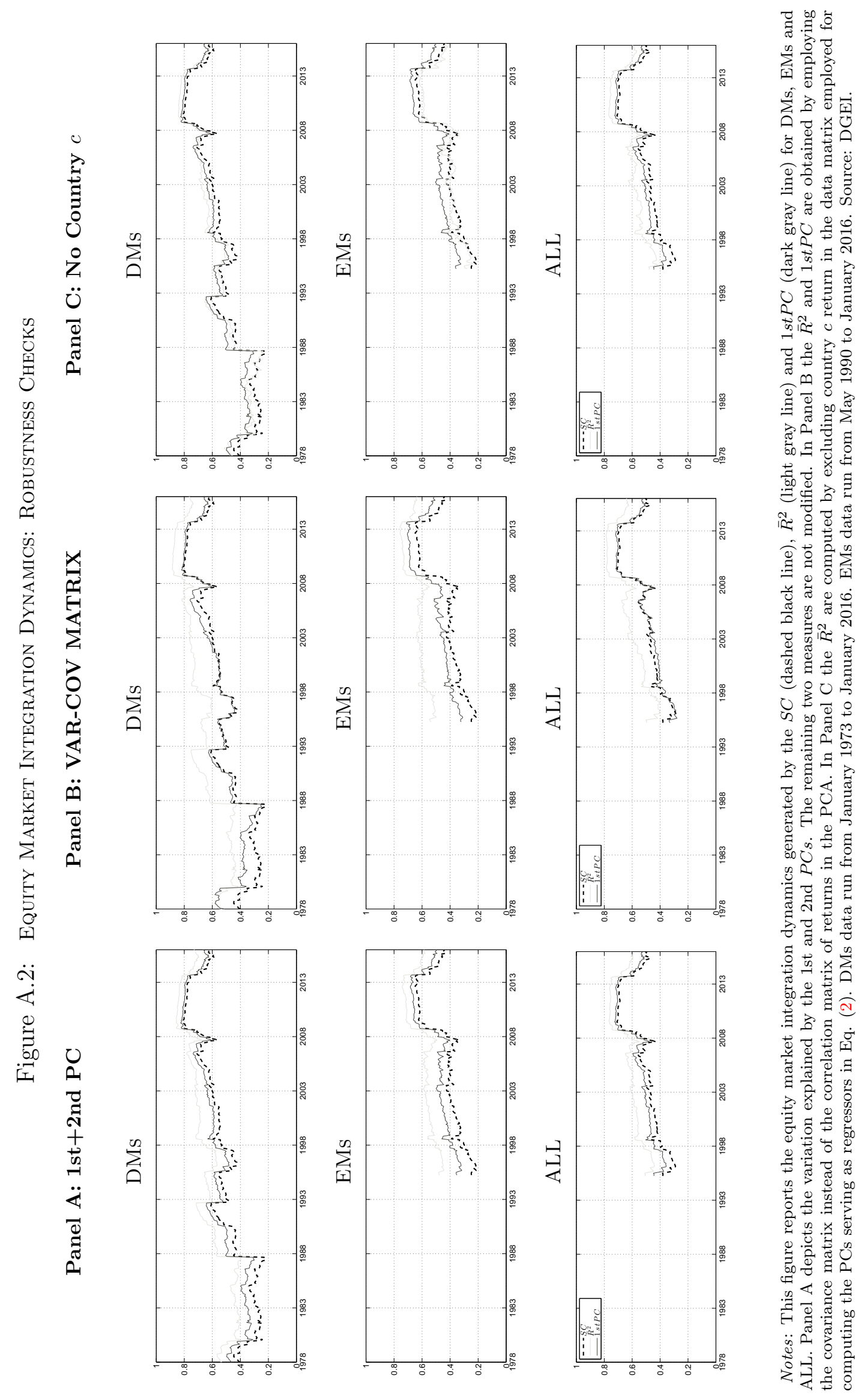


Figure A.3: Equity Market Integration Patterns: Robustness Checks

Panel A: ARMA(P,Q)

DMs

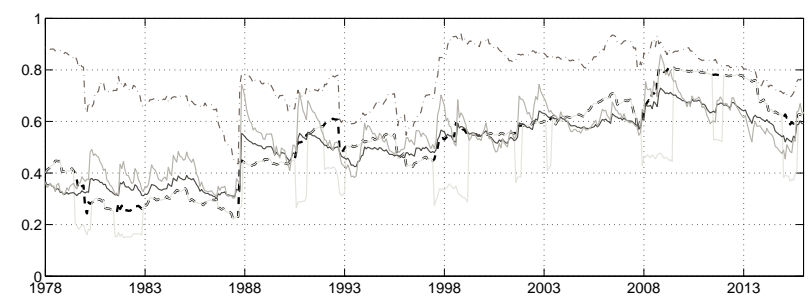

EMs

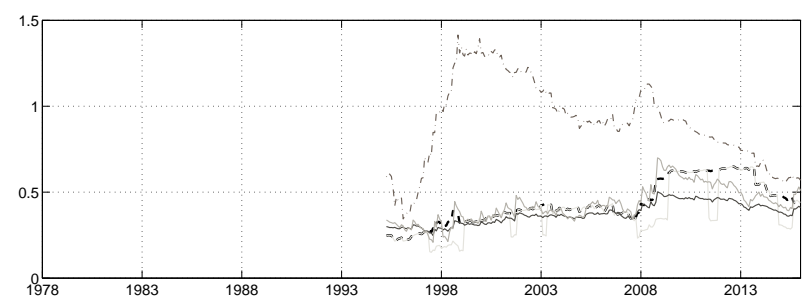

ALL

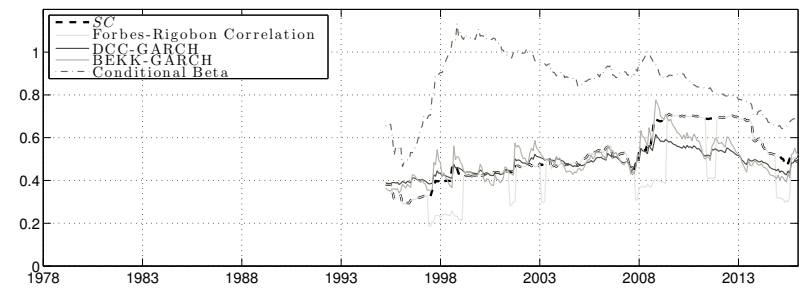

Panel B: Asymmetric Estimations

DMs

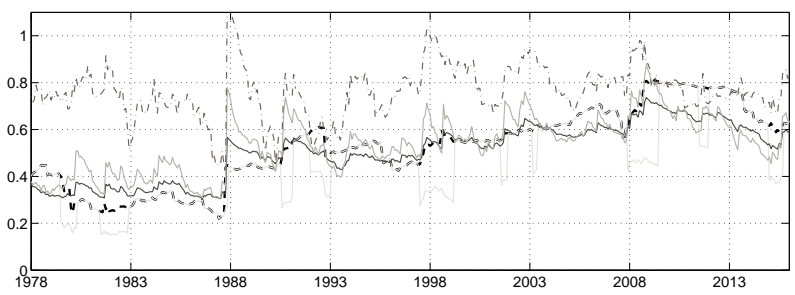

EMs

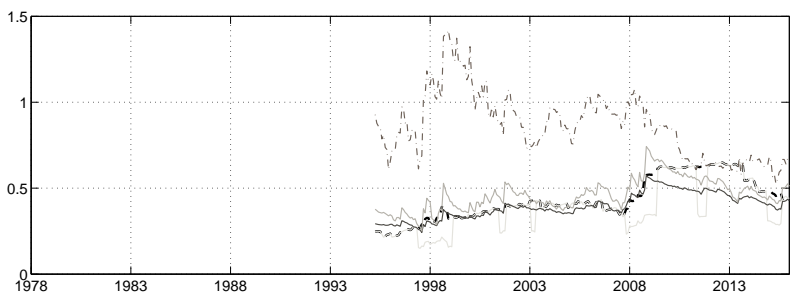

ALL

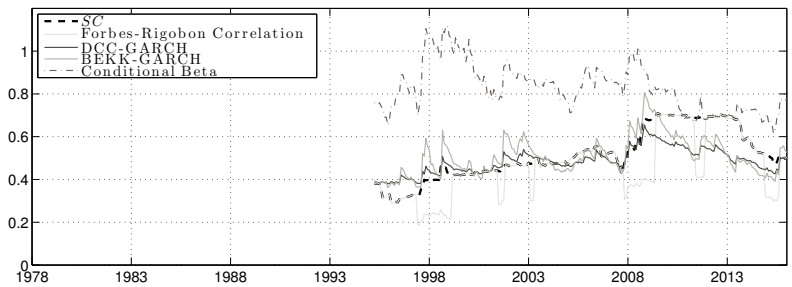

Notes: This figure depicts the equity market integration patterns generated by heteroskedasticity-adjusted measures along with the $S C$ (dashed black lines) for DMs, EMs and ALL. In Panel A the measures DCCGARCH, BEKK-GARCH and Conditional Beta are calculated using the BIC criterion to determine the optimal $p$ and $q$ in ARMA $(\mathrm{p}, \mathrm{q})$ and the Forbes-Rigobon Correlation was estimated using a one-year variance correction $\delta$. Panel B depicts ADCC-GARCH, ABEKK-GARCH and Conditional Beta assuming an asymmetric volatility model. DMs data run from January 1973 to January 2016. EMs data run from May 1990 to January 2016. Source: DGEI. 
Figure A.4: Equity Market Integration: Unconditional Correlation vs. An Alternative MeAsure

DMs

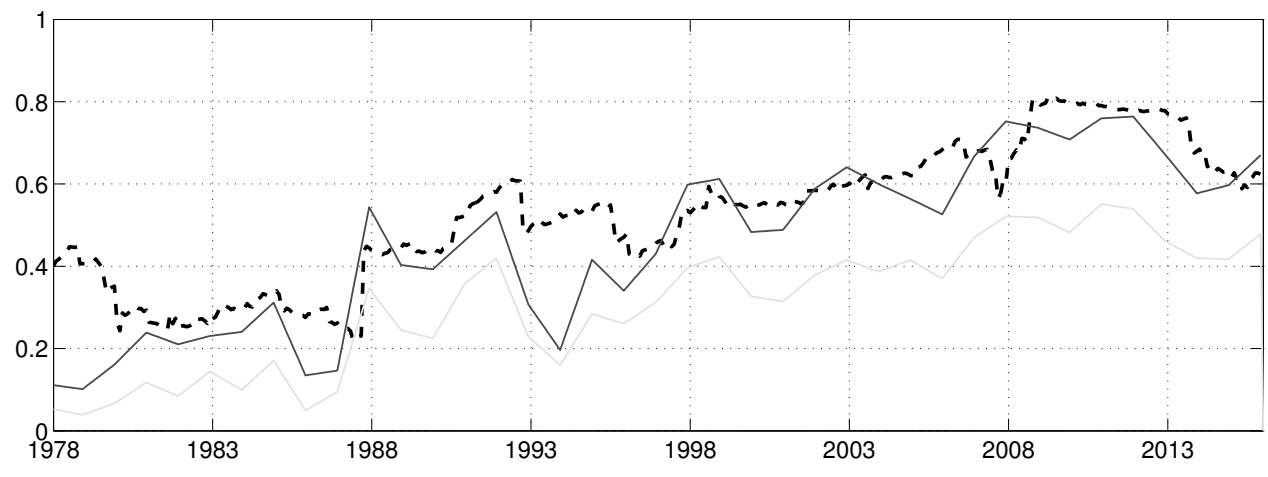

EMs

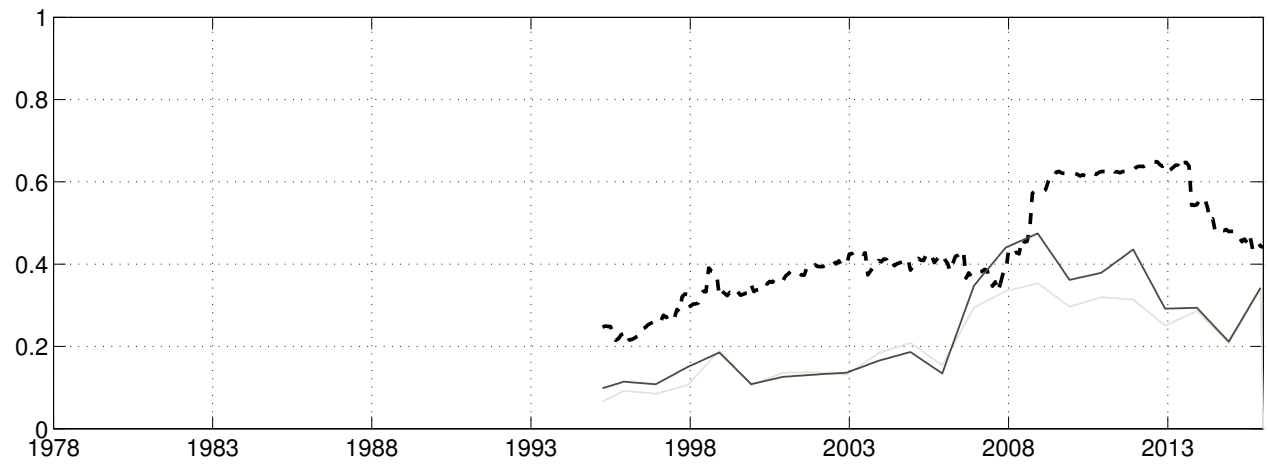

ALL

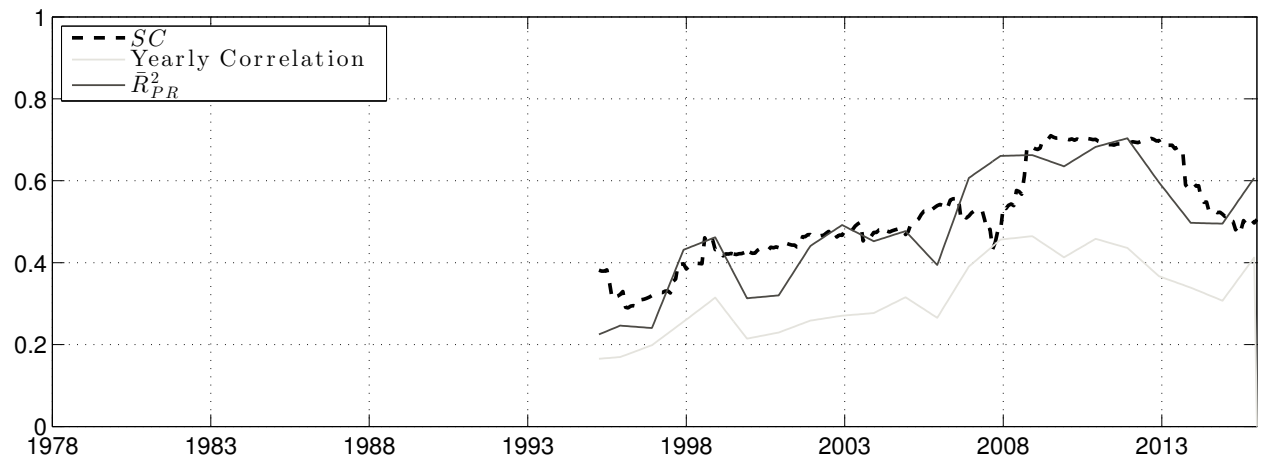

Notes: This figure reports the equity market integration pattern generated by $(i)$ the $S C$ estimated as described in Section 3 using monthly data (dashed black line); (ii) the yearly correlation (light gray line) and (iii) the Pukthuanthong and Roll (2009)'s alternative measure (dark gray line). For each country, a correlation is computed with at least 50 daily returns during each calendar year. The yearly correlation is estimated for each pair of countries during each calendar year using daily returns. The correlations are averaged across countries within each group. The $\bar{R}_{P R}^{2}$ is estimated following the empirical strategy described in Section 7 of Pukthuanthong and Roll (2009) using daily country returns. The number of global factors is chosen such that they account for $90 \%$ of total volatility in the covariance matrix. The proxies for global factors are the first six, eight and ten principal components for DMs, EMs and ALL, respectively. DMs data run from 1/2/1973 to 2/15/2016. EMs data run from 31/5/1990 to 2/15/2016. Source: DGEI. 


\section{B The R-square vs. The 1st PC: Additional Insights}

\section{B.1 Empirical Evidence}

Table B.1: Additional Evidence: $\bar{R}^{2}$ vs. 1 stPC

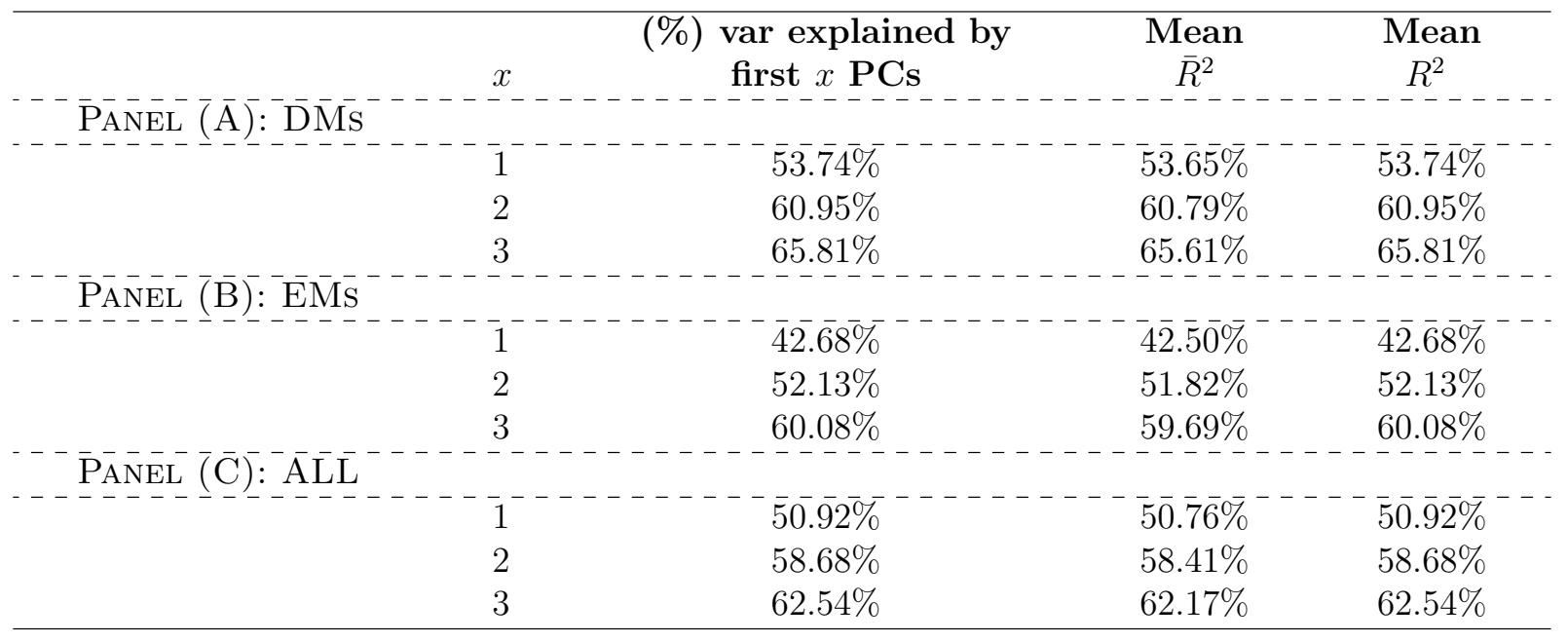

Notes: This table illustrates the relation between $1 s t P C$ and $\bar{R}^{2}$. Variance explained by first $x$ PCs (column 2) is obtained from PCA using the correlation matrix of country index returns. $\bar{R}^{2}$ (column 3) and $R^{2}$ (column 4) are obtained from regression Eq. (2). DMs data run from January 1973 to January 2016. EMs data run from May 1990 to January 2016. Source: DGEI.

\section{B.2 A Two Country-One PC Example}

The following example illustrates that $\bar{R}^{2}$ and 1 stPC give rise to almost identical results. The following calculations are based on the procedure presented in Section 3.2. For simplicity, assume $C=2$ and $K=1$. That is, we have two countries with one global factor driving the individual returns $r_{i}, i=1,2 . r_{i}=\left(r_{i 1}, \ldots, r_{i T}\right)^{\prime}$ being a vector of past $T$ returns for country $i$. The correlation matrix between the countries is given by

$$
\mathrm{P}=\left(\begin{array}{ll}
1 & \rho \\
\rho & 1
\end{array}\right)
$$

with eigenvalues $\lambda_{1}=1+\rho, \lambda_{2}=1-\rho$, and corresponding eigenvectors $v_{1}=(1,1)^{\prime}, v_{2}=(1,-1)^{\prime}$. Assume that $\rho<0$. Then, the proportion of variance explained by the first principal component 
is given by

$$
\text { prop. of var. explained by } 1 \text { st } \mathrm{PC}=\frac{\lambda_{1}}{\lambda_{1}+\lambda_{2}}=\frac{1}{2}(1+\rho) \text {, }
$$

where $\rho=r_{1}^{\prime} r_{2} / \sqrt{\left(r_{1}^{\prime} r_{1}\right)\left(r_{2}^{\prime} r_{2}\right)}$. Following Eq. (1), the corresponding global factor is defined as $f_{1}=r_{1}+r_{2}$. Regressing returns $r_{i}$ on $f_{1}$ according to eq. (2) yields

$$
R_{i}^{2}=\frac{r_{i}^{\prime} f_{1}\left(f_{1}^{\prime} f_{1}\right)^{-1} f_{1}^{\prime} r_{i}}{r_{i}^{\prime} r_{i}}
$$

Substituting $f_{1}$ and rearranging the above equation gives $R_{i}^{2}=\frac{1}{2}\left(1+\frac{r_{1}^{\prime} r_{2}}{\sqrt{\left(r_{1}^{\prime} r_{1}\right)\left(r_{2}^{\prime} r_{2}\right)}}\right)$. This simple illustration confirms that the cross-country average R-square measures exactly the same information as the proportion of variance explained by 1st PC in Eq. (B.2). Please note that in general, for $C>2, R_{i}^{2} \neq R_{j}^{2}$. However, its cross-country average still corresponds to the proportion of variance explained explained by the first PC, as shown in Jong and Kotz (1999) and illustrated in Table B.1. Given that the adjusted R-square is represented by the R-square corrected for the number of predictors, the difference between the variance explained by $x$ components and the mean adjusted $\bar{R}^{2}$ is very small (see columns 2 and 3 ).

\section{Additional Check: Segmentation Index}

In this section we examine whether there is a strong and statistically significant relationship between international diversification benefits and a recently introduced valuation-based measure of segmentation. To this end we compute a segmentation index $(S I)$ along the lines of Bekaert et al. (2011). For robustness, we compute two variants of the SI. The first one makes use of country equity index returns whereas the other relies on sectoral index returns. Both variants - as opposed to Bekaert et al. (2011) - employs aggregate data. Specifically, our country- and sector-based $S I_{\mathrm{s}}$ (i.e., $S I_{C}$ and $S I_{I}$ ) are computed by using TRIs from Level 1 and Level 2 of DGEI, respectively. $S I_{C}$ and $S I_{I}$ are depicted in Figure C.1. Not surprisingly, segmentation is decreasing over time. Therefore, a positive relationship between diversification benefits and segmentation should be observed (i.e., diversification benefits decrease as equity markets segmentation decreases). Counterfactually, we observe a negative relationship between 
the diversification benefits measure and our segmentation indexes. This is confirmed by both average correlations (see Table C.1) and regression coefficients (see Table C.2).

Figure C.1: Equity Market Segmentation Index: A Valuation-Based Measure

\section{DMs}

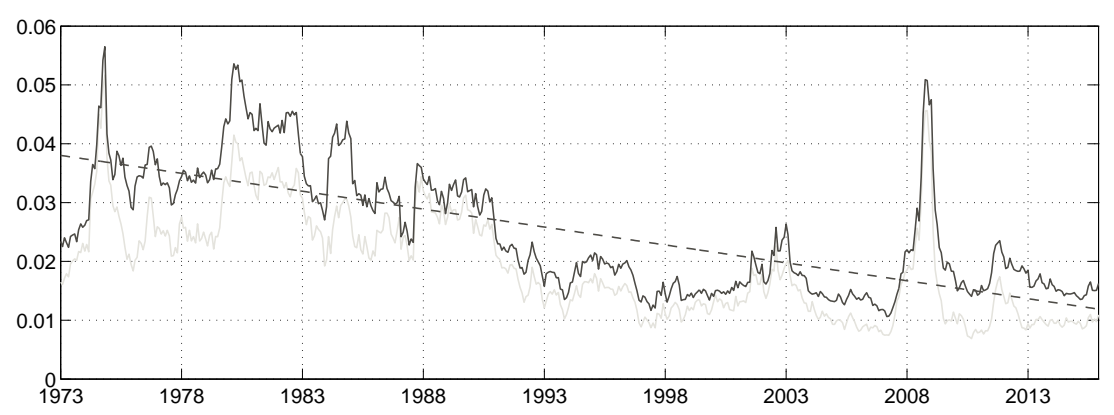

EMs

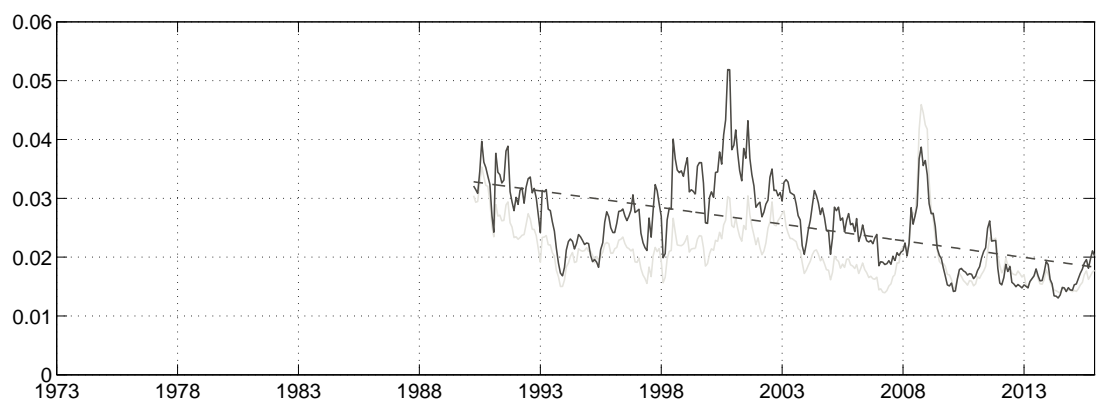

ALL

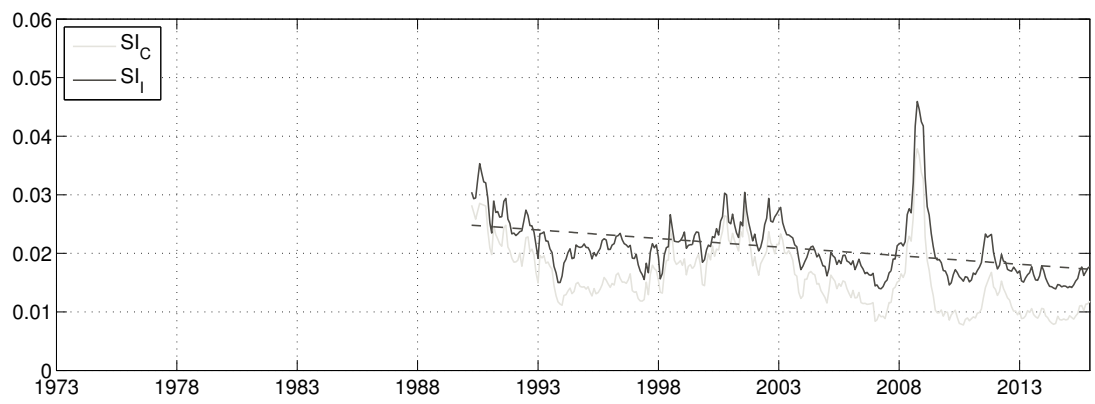

Notes: This figure reports the simplified $\left(S I_{C}\right.$, light grey line) and the original $\left(S I_{I}\right.$, dark grey line) segmentation index as proposed by Bekaert et al. (2011). $S I_{I}$ depicts the cross-country average of individual equity market segmentations. The segmentation for each country is the value-weighted sum of the absolute differences between local and global industry's earnings yields. Industries were added to the calculation at the time they became available in the database. $S I_{c}$ depicts the equal-weighted cross-country average of absolute differences between local country's and global earnings yields. For $S I_{I}$ calculation, monthly equity industry portfolio data using Level 2 ICB classification were employed (i.e., BMATR, CNSMG, CNSMS, FINAN, HLTHC, INDUS, OILGS, TECNO, TELCM, and UTILS). For $S I_{C}$, total market indices were used (TOTMK). The global market is the world index (WD). DMs data run from January 1973 to January 2016. EMs data run from May 1990 to January 2016. Source: DGEI. 
Table C.1: Segmentation Index vs. V-CDB: Average Correlation

\begin{tabular}{cccc}
\hline & DMs & EMs & ALL \\
\hline$S I_{C}$ & -0.069 & $-0.228^{* * *}$ & $-0.123^{*}$ \\
$S I_{I}$ & $-0.115^{* *}$ & $-0.145^{* *}$ & $-0.167^{* * *}$ \\
\hline
\end{tabular}

Notes: This table presents the average correlation, based on 5-year rolling windows, between diversification benefits (i.e., $\left.V-C D B_{H}\right)$ and integration measures depicted in Figures C.1 for DMs, EMs, and ALL. DMs data run from February 1978 to January 2016, EMs and ALL run from May 1995 to January 2016. Significance of $t$-tests for the correlation coefficient at the $10 \%, 5 \%$ and $1 \%$ levels is denoted by $*, * *$ and $* * *$. 
Table C.2: Market Segmentation vs. Diversification Benefits

\begin{tabular}{|c|c|c|c|c|c|c|}
\hline Panel A : DMs & & $S I_{C}$ & & & $\overline{S S I_{I}}$ & \\
\hline$--1--1$ & (1) & $(2)$ & $(3)$ & $(1)$ & $(2)$ & $(3)$ \\
\hline$\overline{\text { Seg. }} \overline{\text { Index }} \overline{-}-$ & $\begin{array}{c}-0 . \overline{0} 64 \\
(0.050)\end{array}$ & $\begin{array}{c}-\overline{0} .0 \overline{6} \overline{6} \\
(0.050)\end{array}$ & $\begin{array}{l}-0.0 \overline{7} 4 \\
(0.057)\end{array}$ & $\begin{array}{c}-0.1 \overline{3} 6 \\
(0.063)^{* *}\end{array}$ & $\begin{array}{c}-0.1 \overline{3} 9^{-} \\
(0.063)^{* *}\end{array}$ & $\begin{array}{c}-0 . \overline{147} \\
(0.069)^{* *}\end{array}$ \\
\hline & {$[0.059]$} & {$[0.060]$} & {$[0.066]$} & {$[0.081]^{*}$} & {$[0.081]^{*}$} & {$[0.087]^{*}$} \\
\hline TO & & 0.083 & -0.517 & & 0.153 & -0.383 \\
\hline & & $(0.734)$ & $(1.022)$ & & $(0.734)$ & (1.003) \\
\hline & & [0.793] & [1.058] & & {$[0.824]$} & [1.068] \\
\hline EPU & & & -0.011 & & & -0.009 \\
\hline & & & $(0.016)$ & & & $(0.016)$ \\
\hline & & & [0.015] & & & {$[0.015]$} \\
\hline RI & & & 0.003 & & & 0.004 \\
\hline & & & $(0.014)$ & & & $(0.014)$ \\
\hline-------- & --- & - & $-[0.011]$ & - & --- & $-[0.011]$ \\
\hline Adj-R2 & 0.003 & 0.000 & 0.000 & 0.011 & 0.009 & 0.007 \\
\hline Avg Adj-R2 & & & 0.001 & & & 0.009 \\
\hline Panel B : EMs & & $S I_{C}$ & & & $S I_{I}$ & \\
\hline $\bar{\alpha}-{ }_{-}-{ }_{-}-\ldots$ & (1) & $(2)$ & $(3)$ & $(1)$ & $(2)$ & $(3)$ \\
\hline$\overline{\text { Seg. }} \overline{\text { Index }} \overline{-}-$ & $\begin{array}{l}-0 . \overline{184} \\
(0.107)^{*}\end{array}$ & $\begin{array}{c}-0.195 \\
(0.101)^{*}\end{array}$ & $\begin{array}{c}-0.1 \overline{9} 0^{-} \\
(0.101)^{*}\end{array}$ & $\begin{array}{l}-0.0 \overline{9} 2 \\
(0.068)\end{array}$ & $\begin{array}{l}-0.101 \\
(0.065)\end{array}$ & $\begin{array}{l}-0 . \overline{101} \\
(0.067)\end{array}$ \\
\hline & {$[0.098]^{*}$} & {$[0.092]^{* *}$} & {$[0.094]^{* *}$} & {$[0.066]$} & {$[0.065]$} & {$[0.066]$} \\
\hline TO & & 2.132 & $1.581^{*}$ & & 2.072 & 1.365 \\
\hline & & $(1.007)^{* *}$ & $(0.913)$ & & $(1.116)^{*}$ & $(0.966)$ \\
\hline & & {$[1.303]^{*}$} & {$[1.347]$} & & [1.388] & {$[1.357]$} \\
\hline EPU & & & -0.005 & & & -0.007 \\
\hline & & & $(0.009)$ & & & $(0.009)$ \\
\hline & & & {$[0.010]$} & & & {$[0.101]$} \\
\hline RI & & & -0.011 & & & -0.013 \\
\hline & & & $(0.007)$ & & & $(0.007)^{*}$ \\
\hline & & & {$[0.008]$} & & & {$[0.008]$} \\
\hline Adj-R2 & 0.048 & 0.079 & 0.086 & 0.017 & 0.045 & 0.054 \\
\hline Avg Adj-R2 & & & 0.071 & & & 0.039 \\
\hline Panel C : ALL & & $S I_{C}$ & & & $S I_{I}$ & \\
\hline & $(1)$ & $(2)$ & $(3)$ & $(1)$ & $(2)$ & $(3)$ \\
\hline$\overline{\text { Seg. }} \overline{\text { Index }}{ }^{-}-$ & $-0 . \overline{0} 7 \overline{2}$ & $-\overline{0} . \overline{07} \overline{4}$ & $-0.0 \overline{7} 1^{-}$ & $-\overline{0} .1 \overline{3} 1^{-}$ & $-0.1 \overline{3} 9^{-}$ & $-0 . \overline{134}$ \\
\hline & $(0.046)$ & $(0.046)$ & $(0.049)$ & $(0.070)^{*}$ & $(0.070)^{* *}$ & $(0.072)^{*}$ \\
\hline & {$[0.044]^{*}$} & {$[0.045]$} & {$[0.047]$} & {$[0.067]^{*}$} & {$[0.068]^{* *}$} & {$[0.068]^{*}$} \\
\hline TO & & -0.192 & -0.964 & & -0.207 & -0.890 \\
\hline & & $(0.614)$ & $(0.906)$ & & $(0.600)$ & $(0.894)$ \\
\hline & & {$[0.672]$} & {$[0.097]$} & & {$[0.672]$} & {$[0.941]$} \\
\hline $\mathrm{EPU}$ & & & -0.015 & & & -0.014 \\
\hline & & & $(0.011)$ & & & $(0.011)$ \\
\hline & & & {$[0.012]$} & & & {$[0.011]$} \\
\hline RI & & & -0.007 & & & -0.006 \\
\hline & & & $(0.011)$ & & & $(0.011)$ \\
\hline & & & {$[0.010]$} & & & {$[0.010]$} \\
\hline Adj-R2 & 0.011 & 0.008 & 0.013 & 0.024 & 0.024 & 0.027 \\
\hline Avg Adj-R2 & & & 0.011 & & & 0.025 \\
\hline
\end{tabular}

Notes: We regress diversification benefits on the segmentation indexes $S I_{C}$ and $S I_{I}$ (for DMs, EMs and ALL) depicted in Figure C.1 on and a bunch of control variables: trade openness $(T O)$, economic policy uncertainty $(E P U)$ and recession indicator $(R I)$. TO := $(E x p o r t s+I m p o r t s) / G D P($ Country: OECD Total, Units: US Dollar, millions, 2010; Frequency: Quarterly; Source: OECD). EPU := Economic Policy Uncertainty Index for United States (Units: Index; Frequency: Monthly [average of daily figures]; Source: Baker et al. (2015)). RI $:=$ OECD based Recession Indicators for the United States from the Peak through the Trough (Units: +1 or 0; Source: Federal Reserve Bank of St. Louis). Monthly TO figures are obtained using the Chow-Lin inter Chow-Lin interpolation method (Chow and Lin, 1971). All variables are expressed in log-differences except for $E P U$, which is expressed in log-level. A constant is included. DMs: (1) = benchmark regrssion model (Sample: 1978M2-2016M1). (2) = regression model 2 (Sample: 1978M2-2015M9). (3) = regression 2 (Sample: 1995M5-2015M9). (3) = regression model 3 (Sample: 1995M5-2014M6). Newey-West (HAC) standard errors are reported in parentheses. Bootstrapped standard errors (with 10,000 replications) are reported in square brackets. Significance at the $10 \%, 5 \%$ and $1 \%$ levels is denoted by $* * *$ and ***. 


\section{On the Measurement Error}

To quantify the effects of the presence of measurement errors in our empirical estimates we first rely on a simulation exercise. In the spirit of McAvoy (1998), we model the "true" financial integration measure $\left(x_{t}^{*}\right)$ and conditional diversification benefits $\left(y_{t}^{*}\right)$ as latent variables. We simulate the following system:

$$
\left\{\begin{array}{l}
y_{t}=\omega y_{t}^{*}+e_{t} \\
y_{t}^{*}=\alpha+\beta x_{t}^{*}+\xi_{t} \\
x_{t}=x_{t}^{*}+\eta_{t} \\
x_{t}^{*}=\gamma x_{t-1}^{*}+\nu_{t}
\end{array}\right.
$$

where $y_{t}$ and $x_{t}$ are the observed variables, and $e_{t}$ and $\eta_{t}$ capture measurement errors. $y_{t}^{*}$ and $x_{t}^{*}$ are the unobserved true variables, whereas $\xi_{t}$ and $\nu_{t}$ are disturbance terms. For parsimony, all error terms $e_{t}, \xi_{t}, \eta_{t}$ and $\nu_{t}$ are assumed to be normally distributed, mutually independent, white noise processes.

In Table D.1 we present a simulation exercise for the system (d.1)-(d.4) assuming the following parameter values: $\omega=0.5 ; \alpha=0, \beta=-0.6 ; \gamma=0.5$. Based on different signal-to-noise ratio $(S t N)$ values, we study four scenarios: $(i)$ low measurement error $(S t N=0.125)$; $(i i)$ medium measurement error $(S t N=0.375)$; (iii) high measurement error $(\operatorname{St} N=0.6)$; and $(\mathrm{iv})$ very high measurement error $(S t N=0.8)$. In each scenario the adjusted R-square obtained estimating the "true" Eq. (d.2) is compared with the R-square obtained estimating the following noise version of $(d .2)$ :

$$
y_{t}=\theta_{0}+\theta_{1} x_{t}+\varepsilon_{t}
$$

A GMM version of Eq. (D.2) - where four lagged values for the dependent and independent variables are used as instruments - is also estimated. As discussed in Section 6.2 GMM estimations are carried out to account for the presence of measurement errors (see also Carroll et al., 2011). We remark that the standard R-square statistic is not robust under IV estimates. Therefore, as goodness of fit in our GMM estimations a pseudo-adjusted R-square is computed. Our results clearly suggest that when the $S t N_{\mathrm{s}}$ are lower than 0.6, the GMM pseudo adjusted $\mathrm{R}$-square and the true adjusted R-square are very close. Differently, the OLS estimated ad- 
justed R-square and the true adjusted R-square are very close only in the presence of a very low $\operatorname{StN}$ (see Table D.1).

Table D.1: On the measurement error: Simulated results with errors in the Dependent VARiable and Regressor

\begin{tabular}{|c|c|c|c|c|c|c|c|c|}
\hline \multirow[b]{2}{*}{$\begin{array}{l}\text { StNs } \\
\frac{\sigma_{e}}{\sigma_{\xi}}, \frac{\sigma_{\eta}}{\sigma_{\xi}} \\
\end{array}$} & \multicolumn{2}{|c|}{ Case 1} & \multicolumn{2}{|c|}{ Case 2} & \multicolumn{2}{|c|}{ Case 3} & \multicolumn{2}{|c|}{ Case 4} \\
\hline & $\frac{\sigma_{e}}{\sigma_{\xi}}=\frac{\sigma}{\sigma}$ & $=0.125$ & $\frac{\sigma_{e}}{\sigma_{\xi}}=\frac{\sigma_{\eta}}{\sigma_{\xi}}$ & $=0.375$ & $\frac{\sigma_{e}}{\sigma_{\xi}}=$ & $=0.625$ & $\frac{\sigma_{e}}{\sigma_{\xi}}=$ & $=0.800$ \\
\hline & Mean & SD & Mean & SD & Mean & SD & Mean & SD \\
\hline True A & 0.322 & 0.050 & 0.320 & 0.052 & 0.320 & 0.051 & 0.319 & 0.049 \\
\hline Adj R-sc & 0.316 & 0.050 & 0.264 & 0.051 & 0.196 & 0.048 & 0.150 & 0.042 \\
\hline Pseudo Adj R-square (GMM) & 0.316 & 0.048 & 0.291 & 0.052 & 0.251 & 0.046 & 0.217 & 0.046 \\
\hline
\end{tabular}

Notes: Adj R-square estimates based upon simulated data according to the system (D.1). True adj R-square is the observed Rsquare that one obtain from estimating Eq. (d.2). Adj R-square is obtained estimating the Eq. (D.2), whereas Pseudo Adj R-square is computed estimating the (D.2) via GMM and using four lagged values of $y_{t}$ and $x_{t}$ as instruments. The pseudo adjusted R-square is defined as described in Tables 3-5. Parameter values: $\omega=0.5 ; \alpha=0, \beta=-0.6 ; \gamma=0.5$. Sample size is equal to 250 and number of replications is 1,000 .

How large are then the measurement errors in our dataset? To address this issue we follow McAvoy (1998) and Cunningham et al. (2012) and estimate a state-space model of the system in Eq. (D.1) using a Kalman filter. Results are reported in Table D.2. For the sake of brevity we report estimates only for the best performing measures (i.e., $S C, R^{2}$, 1 stPC, $S C$ (ASI), $R^{2}$ (ASI), 1stPC (ASI), as suggested by estimates in Tables 3-5 ). Estimates suggest that only in one case (i.e., $S C$ (ASI) for EMs) the $S t N$ is larger than 0.6. In all the other cases, the $S t N$ is far below 0.6. Taken together, the numbers presented in this section show that measurement errors do not lead to biased adjusted R-square statistics. In particular, if GMM estimates are carried out the effect of the measurement error is negligible.

Table D.2: State-Space model estimation of the system (D.1)

\begin{tabular}{lccc}
\hline & DMs & EMs & ALL \\
\hline SC & 0.230 & 0.463 & 0.375 \\
SC (ASI) & 0.416 & 0.673 & 0.381 \\
& & & 0.190 \\
$\bar{R}^{2}$ & 0.120 & 0.205 & 0.209 \\
$\bar{R}^{2}(\mathrm{ASI})$ & 0.169 & 0.267 & 0.317 \\
& & & 0.256 \\
1 1stPC & 0.297 & 0.325 & 0.234 \\
1 stPC (ASI) & 0.213 & & \\
\hline
\end{tabular}

Notes: StN are estimated using the maximum likelihood approach with a Newton-Raphson optimization process. 


\section{E Financial Integration vs. Diversification Benefits: Ad- ditional Insights}

Figure E.1: Financial Integration vs. Diversification Benefits: Rolling Regressions (ALL)

PANEL A

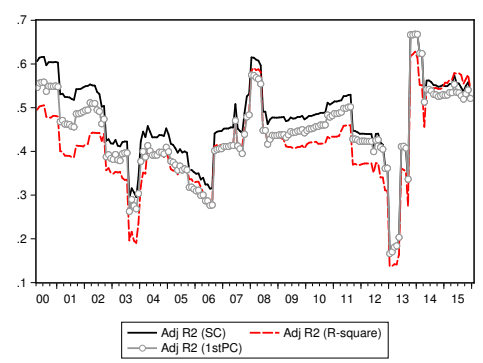

PANEL B

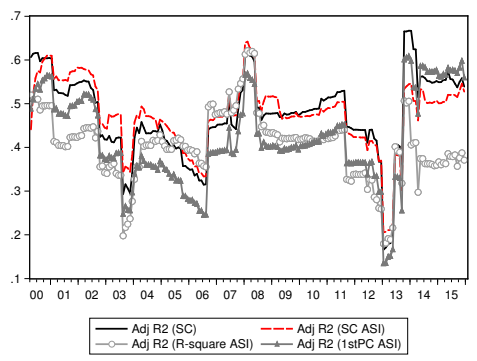

PANEL C

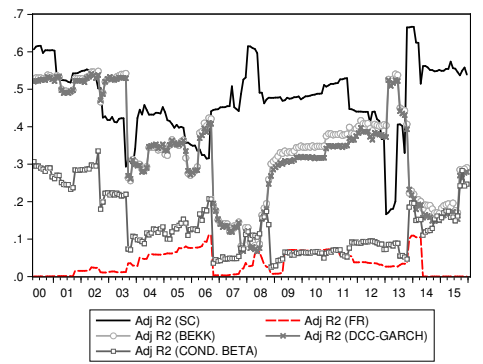

Notes: This figure reports the dynamics of the percentage of variation in international diversification benefits explained by the $S C$ (solid black line) and all the other integration measures. The dynamic regression Adj. R-square of the benchmark model (1) - estimated in Table 5 - is computed using a rolling window of 60 months. A constant is included. All integration measures are computed as described in Section 3.

Table E.1: Explaining International Diversification Benefits (ALL)

\begin{tabular}{cc}
\hline Dependent Variable: $V-C D B^{*}$ & \\
\hline Gets Selection Procedure & $\gamma_{j}:=S C \quad$ Pdj. R-squared \\
$-2 . \overline{2} \overline{8} \overline{9}$ & $(0.243)^{* * *}$ \\
{$[0.239]^{* * *}$}
\end{tabular}

Notes: This table reports the results of the Gets reduction procedure applied to the following regression model:

$V-C D B_{t}^{*}=\alpha+\gamma_{j} \sum_{j=1}^{10} I I_{j, t}+\epsilon_{t}$

where $V-C D B_{t}^{*}$ denotes international diversification benefits and $I I_{j, t}$ (with $j=1, \ldots, 10$ ) represent the ten integration measures plotted in Figures 2 and 3, i.e., $S C, \bar{R}^{2}, 1 s t P C, S C$ (ASI), $\bar{R}^{2}$ (ASI), 1stPC (ASI), FR, DCC-GARCH, BEKK, COND. BETA. Sign restrictions (i.e., $\left.\gamma_{j} \leq 0\right)$ in the model search are imposed following Krolzig (2008). All variables are expressed in logdifferences. Newey-West (HAC) standard errors are reported in parentheses. Bootstrapped standard errors (with 10,000 replications) are reported in square brackets. Pseudo Adj-R2 is the adjusted R-squared calculated in GMM regressions. Pseudo Adj-R2 $=1-\left\{1-\left[\operatorname{corr}\left(V-C D B_{t}^{*}, V \widehat{-C D} B_{t}^{*}\right)\right]^{2}\right\}\left(\frac{n-1}{n-p}\right)$, where $V \widehat{-C D} B_{t}^{*}$ is the fitted value of $V-C D B_{t}^{*}, p$ is the number of explanatory variables and $n$ is the sample size. Employed instruments: lagged values of $V-C D B^{*}$ and regressors (from $t-1$ to $t-5) . V-C D B_{t}^{*}$ here is calculated as the first principal component of all the previously defined diversification benefits measures (i.e., $\left.V-C D B, V-C D B_{A S I}, V-C D B_{B E K K}, V-C D B_{D C C}\right)$. GMM estimation passes the standard tests of instrument validity. Sample: 1995M5-20016:M1. Significance at the $10 \%, 5 \%$ and $1 \%$ levels is denoted by *,** and ***. 


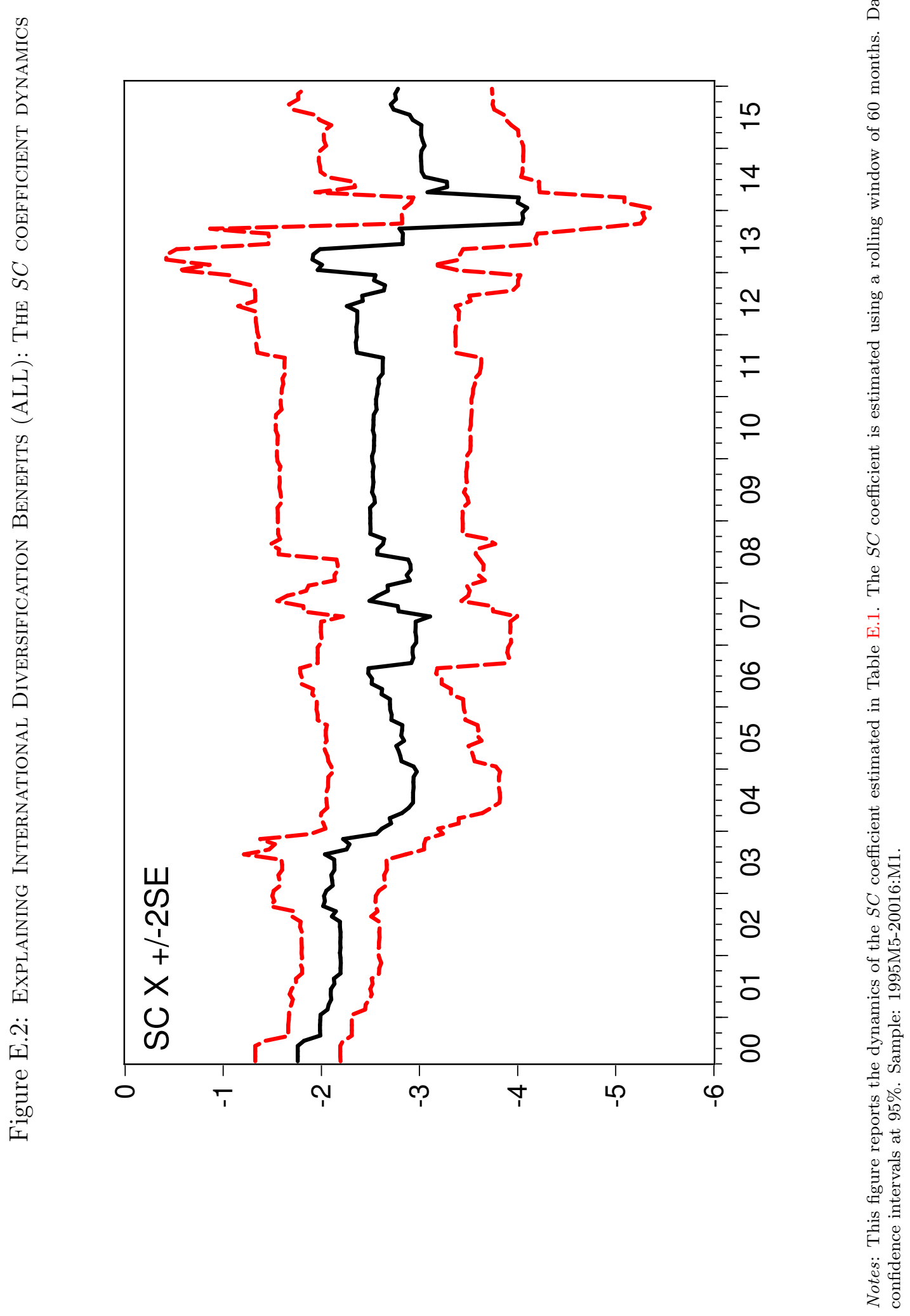




\section{F Financial Integration vs. FDI global share}

Table F.1: Integration Indexes vs. FDI global Share (ALL)

\begin{tabular}{|c|c|c|c|c|c|c|c|}
\hline Panel A: & Standard Measures & & Robust $\mathrm{M}$ & easures & & Adjusted $\mathrm{Me}$ & sures \\
\hline & $S C$ & & $R^{2}$ & $1 s t P C$ & $S C(A S I)$ & $R^{2}(A S I)$ & $1 s t P C(A S I)$ \\
\hline Int. Index $(-1)$ & 0.243 & & 0.411 & 0.294 & 0.189 & 0.343 & 0.234 \\
\hline & $(0.067)^{* * *}$ & & $(0.130)^{* * *}$ & $(0.086)^{* * *}$ & $(0.061)^{* * *}$ & $(0.096)^{* * *}$ & $(0.085)^{* * *}$ \\
\hline & {$[0.071]^{* * *}$} & & {$[0.126]^{* * *}$} & {$[0.087]^{* * *}$} & {$[0.062]^{* * *}$} & {$[0.125]^{* * *}$} & {$[0.085]^{* * *}$} \\
\hline Int. Index (-2) & 0.231 & & 0.368 & 0.257 & 0.162 & 0.341 & 0.191 \\
\hline & $(0.089)^{* *}$ & & $(0.151)^{* *}$ & $(0.100)^{* *}$ & $(0.067)^{* *}$ & $(0.160)^{* *}$ & $(0.092)^{* *}$ \\
\hline & {$[0.093]^{* *}$} & & {$[0.158]^{* *}$} & {$[0.108]^{* *}$} & {$[0.078]^{* *}$} & {$[0.164]^{* *}$} & {$[0.105]^{*}$} \\
\hline Int. Index $(-5)$ & -0.105 & & -0.187 & -0.130 & -0.075 & -0.154 & -0.109 \\
\hline & $(0.046)^{* *}$ & & $(0.099)^{*}$ & $(0.053) * *$ & $(0.021)^{* * *}$ & $(0.069)^{* *}$ & $(0.029)^{* * *}$ \\
\hline & {$[0.052]^{* *}$} & & {$[0.106]^{*}$} & {$[0.064]^{* *}$} & {$[0.031]^{* *}$} & {$[0.084]^{*}$} & {$[0.046]^{* *}$} \\
\hline$\overline{\mathrm{Ad}} \overline{\mathrm{j}}-\overline{\mathrm{R}} \overline{2}{ }^{-}$ & $0.300^{-}$ & & $0 . \overline{2} 59$ & $0 . \overline{3} 01^{-}$ & 0.296 & $0 . \overline{2} \overline{4} 8^{-}$ & 0.251 \\
\hline$\overline{\text { Pseudo Ad }} \overline{\mathrm{Aj}}-\overline{\mathrm{R}} \overline{2}(\overline{\mathrm{G}} \overline{\mathrm{M}} \overline{\mathrm{M}})$ & $\overline{0} . \overline{2} 81^{-}$ & & $\overline{0 . \overline{1} 90^{-}}$ & $\overline{0} \overline{2} \overline{65}{ }^{-}$ & $\overline{0.19 \overline{1}}-$ & $\overline{0} . \overline{1} \overline{50}$ & $\overline{0.08 \overline{6}}$ \\
\hline Panel B & Hetero & edasticity- $A$ & ljusted Measure & & & & \\
\hline & Forbes-Rigobon & BEKK & DCC-GARCH & Cond. Beta & & & \\
\hline Int. Index $(-1)$ & & $\begin{array}{c}0.102 \\
(0.048)^{* *}\end{array}$ & $\begin{array}{c}0.247 \\
(0.119)^{* *}\end{array}$ & $\begin{array}{c}0.126 \\
(0.044)^{* * *}\end{array}$ & & & \\
\hline & & {$[0.050]^{* *}$} & {$[0.117]^{* *}$} & {$[0.050]^{* *}$} & & & \\
\hline Int. Index $(-2)$ & & 0.135 & 0.303 & 0.122 & & & \\
\hline & & $(0.049)^{* * *}$ & $(0.115)^{* *}$ & $(0.038) * * *$ & & & \\
\hline & & {$[0.039]^{* * *}$} & {$[0.095]^{* * *}$} & {$[0.036]^{* * *}$} & & & \\
\hline Int. Index $(-3)$ & -0.030 & 0.089 & 0.167 & 0.069 & & & \\
\hline & $(0.012)^{* *}$ & $(0.031)^{* * *}$ & $(0.059)^{* * *}$ & $(0.030)^{* *}$ & & & \\
\hline & {$[0.013]^{* *}$} & {$[0.037]^{* *}$} & {$[0.082]^{* *}$} & {$[0.039]^{*}$} & & & \\
\hline Int. Index $(-4)$ & -0.027 & 0.101 & 0.161 & 0.119 & & & \\
\hline & $(0.012)^{* *}$ & $(0.031) * * *$ & $(0.064)^{* *}$ & $(0.035) * * *$ & & & \\
\hline & {$[0.014]^{*}$} & {$[0.033]^{* * *}$} & {$[0.079]^{* *}$} & {$[0.040]^{* * *}$} & & & \\
\hline Int. Index $(-5)$ & -0.042 & & & & & & \\
\hline & $(0.013) * * *$ & & & & & & \\
\hline${ }^{-}{ }^{-} \mathrm{d} \overline{\mathrm{j}}-\overline{\mathrm{R}} \overline{2}^{-}$ & 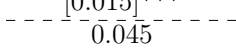 & $\overline{0} . \overline{2} \overline{5} 9^{-}$ & $0 . \overline{2} 5 \overline{9}^{--}$ & $\overline{0} . \overline{1} \overline{7} 8^{-}$ & & & \\
\hline 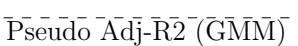 & $\overline{0.0} \overline{09}{ }^{-}$ & $\overline{0} . \overline{2} \overline{0} \overline{4}$ & $\overline{0 . \overline{1} 9 \overline{9}}-$ & $\overline{0} \overline{1} \overline{2} 2^{-}$ & & & \\
\hline
\end{tabular}

Notes: We regress a measure of FDI global share (i.e., a global indicator of capital mobility among countries) on each of the integration measures depicted in Figures 2 and 3. The optimal number of lags for each equation is selected using the Gets procedure described in Hendry and Krolzig (2003, 2005). Results are reported for the country group ALL only. The global FDI share is obtained as a GDP-weighted average of cross-country FDI shares. FDI share at country level is defined as the sum of inward and outward FDI stocks divided by GDP. FDI share data are retrieved from UNCTAD. Data are available at annual frequency and are converted in quarterly using the Chow-Lin interpolation method (Chow and Lin, 1971). Quarterly financial integration measures are obtained as averages of monthly figures. All variables are expressed in log-differences. A constant is included in the regressions. Newey-West (HAC) standard errors are reported in parentheses. Bootstrapped standard errors (with 10,000 replications) are reported in square brackets. Pseudo Adj-R2 is the adjusted R-squared calculated in GMM regressions. Pseudo Adj-R2 $=1-\left\{1-\left[\operatorname{corr}\left(F D I_{t}, \widehat{F D I}_{t}\right)\right]^{2}\right\}\left(\frac{n-1}{n-p}\right)$, where $\widehat{F D I}_{t}$ is the fitted value of $F D I_{t}, p$ is the number of explanatory variables and $n$ is the sample size. Employed instruments: lagged $F D I$ (from $t-1$ to $t-4$ ) and lagged integration index (from $t-6$ to $t-8)$. GMM estimation passes the standard tests of instrument validity. Sample: 1996Q1-2014Q4. Significance at the $10 \%, 5 \%$, and $1 \%$ levels is denoted by ${ }^{*},{ }^{* *}$, and ${ }^{* * *}$. 


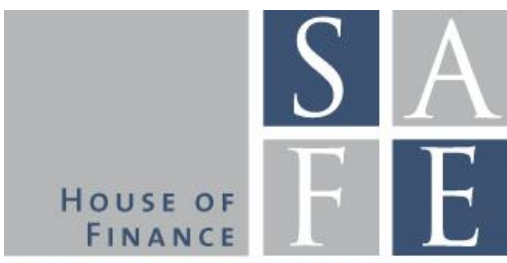

WORKING PAPER SERIES

\section{Recent Issues}

No. 158 Michael Donadelli, Renatas Kizys, Max Riedel

No. 157 Steffen Meyer, Linda Urban, Sophie Ahlswede

No. 156 Reint Gropp, Thomas Mosk, Steven Ongena, Carlo Wix

No. 155 Vahid Saadi

No. 154 Brigitte Haar

No. 153 Julia Hirsch, Uwe Walz

No. 152 Viral Acharya, Tim Eisert, Christian Eufinger, Christian Hirsch

No. 151 Michael Schneider, Fabrizio Lillo, Loriana Pelizzon

No. 150 Vanya Horneff, Raimond Maurer, Olivia S. Mitchell

No. 149 Massimiliano Caporin, Aleksey Kolokolov, Roberto Renò

No. 148 Sven-Thorsten Jakusch

No. 147 Andreas Hackethal, Sven-Thorsten Jakusch, Steffen Meyer
Globally Dangerous Diseases: Bad News for Main Street, Good News for Wall Street?

Does feedback on personal investment success help?

Bank Response To Higher Capital Requirements: Evidence From A QuasiNatural Experiment

Mortgage Supply and the US Housing Boom: The Role of the Community Reinvestment Act

Shareholder Wealth vs. Stakeholder interests? Evidence from Code Compliance under the German Corporate Governance Code

The Financing Dynamics of Newly Founded Firms

Whatever it Takes: The Real Effects of Unconventional Monetary Policy

How Has Sovereign Bond Markets Liquidity Changed? - An Illiquidity Spillover Analysis

Putting the Pension back in 401 (k) Plans: Optimal versus Default Longevity Income Annuities

Systemic Co-Jumps

On the Applicability of Maximum Likelihood Methods: From Experimental to Financial Data

Taring all Investors with the same Brush? Evidence for Heterogeneity in Individual Preferences from a Maximum Likelihood Approach 